\title{
Planeación participativa de políticas públicas: la formulación de la política pública de empleo y emprendimiento en el municipio de San Martín, Colombia ${ }^{1}$
}

\author{
Víctor David Sánchez Calvo²
}

\section{Resumen:}

Este artículo aborda la planeación participativa en la formulación de políticas públicas en Colombia, a partir del estudio de caso del proceso de formulación de la política pública de empleo y emprendimiento, en el municipio de San Martín, departamento de Cesar, desarrollado entre septiembre de 2016 y mayo de 2017. El análisis se centra en el proceso de organización de diversos actores - comunidad, institucionalidad pública y privada- que buscan atender una problemática de carácter público en un territorio que, por sus condiciones geográficas y las características de sus suelos, desde el año 2012 estructuró su desarrollo económico basado en el sector hidrocarburos.

En coherencia con lo anteriormente expuesto, este artículo expone el análisis del proceso de inclusión de este problema de interés público en la agenda política local, describe el proceso participativo de formulación de la política pública, así como los resultados obtenidos. El estudio es de carácter descriptivo en tanto identifica y describe los factores que ejercen influencia en el proceso estudiado (Martínez, 2006, p.171); para ello recurrió al análisis de información primaria y secundaria, tuvo como estrategia transversal

\footnotetext{
${ }^{1}$ Este artículo es producto del trabajo de grado para optar al título de Magíster en Planeación para el Desarrollo de la Universidad Santo Tomás, Bogotá, Colombia. La investigación fue realizada bajo la dirección de Angie Carolina Torres Ruiz, en el marco de la línea Desarrollo, planeación participativa y políticas públicas del grupo de investigación Conflictos sociales, género y territorio. Agradezco el apoyo de la comunidad de San Martín, Cesar, sus sectores productivos, sus líderes comunitarios, al Concejo y a la Alcaldía Municipal, así como al equipo técnico del PNUD y la ETH, quienes hicieron posible esta experiencia y reflexiones, con las que espero, además, continuar profundizando los caminos posibles de la planeación participativa de políticas públicas en Colombia.

${ }^{2}$ Economista, Consultor del Programa de las Naciones Unidas para el desarrollo PNUD.
} 
la observación participante permitida al investigador por su rol de facilitador en el proceso que contó con grupos de discusión en talleres participativos, cuyos documentos memoria fueron analizados a través de la técnica de análisis de contenido.

El ejercicio identifico una débil presencia institucional en función de trabajo decente, generación y protección de empleo, así como la percepción de desamparo en las zonas rurales y una baja gestión local para promover desarrollo humano, También presenta algunas barreras que enfrenta el campesino para garantizar sus ingresos.

Se evidenció en el proceso que el abandono estatal que manifestó la comunidad, y que podría interpretarse como debilidad institucional, es causa del desinterés de participar en escenarios de planeación participativa, asunto agravado por la falta de compromiso y de cumplimiento de las autoridades públicas y los actores privados en la implementación de los proyectos definidos de manera participativa.

Palabras clave: planeación participativa, políticas públicas, empleo y emprendimiento, San Martin

\section{Abstract}

This article examines participatory planning in the formulation stages of public policy in Colombia. It focuses the case study of San Martin - department of Cesar - and its employment and entrepreneurship public policy formulation process, developed between September 2016 and May 2017. The analysis centers on the organization of diverse actors community and public and private institutions - that seek to address a problem of public characer in a territory which has adopted since 2012 a hydrocarbons exploitation strategy for its economic development, due to its geographic conditions and characteristics of its 
soils.

Building on the above, this article provides an analysis of the inclusion process of this - public interest - problem in the local political agenda. It describes the participatory process in the formulation of public policy as wells as the obtained results. The study is of descriptive character as it identifies and describes factors which influence the process under enquiry (Martinez, 2006). For this, primary and secondary data analysis was carried out, applying observations as a cross-cutting tool by the investigator in his role as facilitator of the methodological process developed with the actors. Focus groups discussions in participatory workshops provided the main source of information, in which meeting minutes where analyzed applying the content analysis technique.

The exercise identifies a weak institutional presence in terms of decent work, employment generation and protection, as well as the perception of homelessness in rural areas and low local management to promote human development. It also presents some barriers faced by peasants to guarantee their income.

It was evidenced in the process that the state's abandonment of the community, which could be interpreted as institutional weakness, is a cause of the lack of interest in participating in participatory planning scenarios, a matter aggravated by the lack of commitment and compliance of public authorities and private actors in the implementation of the projects defined in a participatory manner.

Key words: participatory planning, public policies, employment and entrepreneurship, San Martín 


\section{Introducción}

En Colombia, luego de la Constitución Política de 1991, la planeación se convirtió en el eje central de las políticas públicas, transversal en lo sectorial y con convergencia en lo nacional y territorial. Tal y como lo menciona Forero, "la planeación se redefinió como un proceso continuo e iterativo; adoptó el carácter de indicativa para la sociedad y obligatoria para el Estado y - su característica más importante - se hizo participativa" (2000, p.45). Este componente de participación es una apuesta que debería reducir el principal y más constante problema de la toma de decisiones públicas ante las problemáticas sociales, problema descrito por Young (como citó Palacio) de la siguiente manera:

“(...) lejos de lo que puedan suponer los modelos formales, no es la persuasión la que determina cuáles son las mejores medidas o cuáles son las decisiones más justas, pues el elemento deliberativo que debiera orientar las cuestiones de interés colectivo queda pervertido, al ser los ciudadanos excluidos de los procedimientos para la toma de decisiones, en la que primaría, en realidad, la razón técnica o instrumental, carente de toda carga valorativa". (2011, p.80).

Así, desde 1991 en adelante, el país entró en un proceso de transformación progresiva de las políticas públicas que debían incorporar, además de procesos de planeación, procesos de participación ciudadana conforme con el desarrollo de la normatividad derivada de la nueva Carta Política. En este contexto, y después de transcurridos quince (15) años desde la reforma constitucional, en este artículo se presenta el análisis del proceso de formulación de una política pública específica, la política pública 
de empleo ${ }^{3}$ y emprendimiento ${ }^{4}$, a partir del estudio de caso del proceso desarrollado en el municipio en de San Martín, en el departamento del Cesar.

El proceso de formulación en San Martín, Cesar, fue seleccionado como caso de estudio en tanto que busca atender una problemática que se ha identificado como de carácter público en un territorio que, por sus condiciones geográficas y las características de sus suelos, desde el año $2012^{5}$ estructuró su desarrollo económico en el sector hidrocarburos y contó con espacios de participación ciudadana para todos los sectores económicos y productivos representativos en el territorio y todas las veredas y corregimientos, en concordancia con lo establecido en la Ley Estatutaria 1757 de 2015 de Participación Ciudadana, y en tanto el investigador tuvo acceso directo a la información por su rol de facilitador.

Por otra parte, y como se evidenciará más adelante en este documento, la presión que ejerció la comunidad por no permitir en su territorio el fracking como técnica de exploración de pozos petroleros, despertó la atención de instituciones de carácter nacional con y sin presencia en el territorio lo que conllevo a que fuera necesario tomar decisiones y llevar a cabo acciones para identificar en un trabajo articulado con la comunidad y diferentes actores cual sería la forma correcta de potenciar el crecimiento económico del municipio a partir de otros sectores productivos.

\footnotetext{
${ }^{3}$ Se entiende por empleo el conjunto de funciones, deberes y responsabilidades que han de ser atendidos por una persona natural, para satisfacer necesidades permanentes de la administración pública y de entidades particulares. Los deberes, funciones y responsabilidades de los diferentes empleos son establecidos por la Constitución, la ley o el reglamento, o asignados por autoridad competente (Decreto nacional 1042, 1978).

${ }^{4}$ Puede definirse como el desarrollo de un proyecto que persigue un determinado fin económico, político o social, entre otros, y que posee ciertas características, principalmente que tiene una cuota de incertidumbre y de innovación.

5 La compañía Ecopetrol confirmo el hallazgo de un nuevo yacimiento de petróleo en el pozo exploratorio Tisquirama Este-1, ubicado en el municipio de San Martin, Cesar. Abril 26 - 2012
} 
Por lo anterior este proyecto fue apoyado y financiado por la Estrategia Territorial Para La Gestión Equitativa y Sostenible del Sector Hidrocarburos ${ }^{6}$ (ETH), como acción demostrativa $^{7}$ alineada con su programa Convive ${ }^{8}$ propuesta desde Ministerio del Interior.

Así, este documento, dividido en cuatro secciones, analiza el proceso de inclusión de un problema en la agenda política del municipio de San Martín y describe cómo fue el proceso de formulación participativa de la política pública de empleo y emprendimiento con la comunidad, los sectores productivos, la institucionalidad pública y privada, junto con los resultados de los ejercicios participativos.

En la primera sección se presenta la revisión del marco institucional de la planeación participativa y sus implicaciones en la formulación de políticas públicas en Colombia; en la segunda sección se ofrecen los enfoques, modelos y aproximaciones que diferentes autores aportan en torno a la inserción de un problema de interés público en la agenda política y qué debería contener una política pública participativa; en el tercer apartado se presenta el diseño metodológico y los resultados del proceso participativo desarrollado en San Martín, así como una breve descripción del contexto, las dinámicas socio-económicas del municipio de San Martín y sus implicaciones con en el desarrollo

\footnotetext{
${ }^{6}$ El proyecto de la Estrategia Territorial para la Gestión Equitativa y Sostenible del Sector Hidrocarburos (ETH) es una iniciativa del Gobierno Nacional que promueve las visiones participativas del desarrollo humano sostenible en las regiones con actividad hidrocarburífera, como instrumento para la construcción de la paz territorial con el asesoramiento y apoyo técnico del PNUD.

${ }^{7}$ Las Acciones Demostrativas o inversiones para el desarrollo humano sostenible son iniciativas territoriales que surgen de los procesos de diálogo en el marco de la (ETH), con el propósito de generar confianza y contribuir a la transformación de las relaciones entre los actores. Estas inversiones están enfocadas a mejorar la gobernanza democrática y el crecimiento económico incluyente de la población y permiten entrelazar esfuerzos y alianzas entre los actores y programas de la Estrategia para demostrar que mediante procesos de diálogo se puede contribuir al desarrollo local.

${ }^{8}$ Este programa, liderado por el Ministerio del Interior, tiene como objetivo generar mecanismos para la prevención y transformación de conflictos sociales que se generan en las regiones con presencia de actividad hidrocarburífera. A través de esta actividad se busca atender los conflictos sociales e intervenir en crisis de orden público, haciendo uso del diálogo, la participación y la inclusión social.
} 
humano y sostenible. Finalmente, el cuarto apartado expone las conclusiones y recomendaciones del estudio.

\section{Planeación participativa Colombia: marco normativo y desafíos}

Los desafíos que se presentan en los procesos de planeación desarrollados por todas las sociedades y sus instituciones, encuentran su respuesta en estrategias que vinculan el espacio-tiempo, los procesos sociales, económicos, culturales y normativos. Así, la respuesta a estos desafíos, hace que la planeación adquiera "la categoría de proceso al desarrollarse de manera intencionada, lógica y secuencial, mediante un conjunto de momentos o etapas complementarias que, interconectadas, actúan como un sistema abierto, flexible y sinérgico, permitiéndole conjugar un objetivo superior: el desarrollo del territorio.” (Tamayo \& Sánchez, 2008, p.16).

En Colombia, desde el año 1991, la nueva Constitución Política formalizó y reglamentó la planeación, como una herramienta que, en el largo plazo, se alimenta de forma descentralizada y democrática. Desde entonces, en lo nacional y lo territorial, distintas leyes, decretos y acuerdos regulan y exigen el desarrollo de la planeación con participación. Así, la planeación se convirtió en el eje central de las políticas de la nación, transversal en lo sectorial y con convergencia en lo nacional y territorial. Como lo menciona Forero, "la planeación se redefinió como un proceso continuo e iterativo; adoptó el carácter de indicativa para la sociedad y obligatoria para el Estado y - su característica más importante - se hizo participativa" (2000, p.45).

Dicha participación abrió las puertas al reconocimiento de derechos de sectores poblacionales invisibilizados, con especial énfasis en las comunidades étnicas, aunque Rodrigo Uprimny (2001) identificó que dentro de la Constitución de 1991 se abrieron 
espacios para nuevas formas de participación democrática, en las cuales se involucraron no solo los indígenas y negritudes, sino también otras identidades, como las basadas en la diferencia e identidad sexual.

En este nuevo escenario de apertura democrática fue creado, entre otras instancias, el Sistema Nacional de Planeación (SNP), compuesto por el Consejo Nacional de Planeación y los consejos territoriales de 32 departamentos $^{9}$ y 1067 municipios ${ }^{10}$ del país. Los miembros de los consejos de planeación, en su mayoría líderes de organizaciones que tienen a su alrededor redes de apoyo, se convirtieron en la instancia participativa responsable del seguimiento, el control social y político de estos procesos.

Desde su creación, el SNP, como espacio privilegiado de la planeación participativa en Colombia, ha sido objeto de críticas e intentos de reforma; uno de los foros que dio paso a la reestructuración del sistema fue el realizado el 6 de junio de 2013 en la Comisión Primera del Senado de la República en donde se trató la necesidad de cambio o reglamentación de la Ley $152^{11}$ de 1994, con el propósito de mejorar las condiciones para el ejercicio efectivo de la planeación participativa y los presupuestos participativos. En ese foro, Mauricio Perfetti, entonces subdirector sectorial del Departamento Nacional de

\footnotetext{
${ }^{9}$ Departamento: de acuerdo con el Artículo 298 de la actual Constitución Política de Colombia, es una entidad territorial que goza de autonomía para la administración de los asuntos seccionales y la planificación y promoción del desarrollo económico y social dentro de su territorio en los términos establecidos por la Constitución y las leyes. Los departamentos ejercen funciones administrativas, de coordinación, de complementariedad de la acción municipal, de intermediación entre la Nación y los municipios y de prestación de los servicios que determinen la Constitución y las leyes. (DANE)

${ }^{10}$ Municipio: de acuerdo con el Artículo 311 de la actual Constitución Política de Colombia y la Ley 136 de Junio 2 de 1994, es la entidad territorial fundamental de la división político-administrativa del Estado, con autonomía política, fiscal y administrativa dentro de los límites que le señalen la Constitución y las leyes de la República. Sus objetivos son la eficiente prestación de los servicios públicos a su cargo, la construcción de las obras que demande el progreso local, la ordenación de su territorio, la promoción de la participación comunitaria en la gestión de sus intereses y el mejoramiento social y cultural de sus habitantes. (DANE)

${ }^{11}$ Por la cual se establece la Ley Orgánica del Plan de Desarrollo, tiene como propósito establecer los procedimientos y mecanismos para la elaboración, aprobación, ejecución, seguimiento, evaluación y control de los planes de desarrollo.
} 
Planeación (DNP), ratificaba que dentro del plan de desarrollo nacional "Prosperidad Para Todos” del gobierno del Presidente Juan Manuel Santos (2014 - 2018), se impulsaba una agenda nacional de participación ciudadana con base en cinco (5) ejes fundamentales: el fomento al sistema nacional de planeación e impulso a la presupuestación participativa; el fortalecimiento a los mecanismos, canales e instancias de planeación participativa; el fortalecimiento de expresiones asociativas de la sociedad civil y, el fortalecimiento de la cultura ciudadana y los sistemas de información y gestión.

Fue en ese foro en el que el DNP presentó, por primera vez, el proyecto de ley estatutaria de participación ciudadana, en el que se destacaron elementos fundamentales: la inclusión de un conjunto de principios y definiciones sobre la participación ciudadana, su espíritu y alcance; la revisión de los mecanismos directos, modificando algunos requisitos y procedimientos de conformidad con la Constitución Política y, finalmente, un capítulo sobre rendición de cuentas y control social e incentivos, garantías y financiamiento.

Dicho proyecto se concretó en la Ley estatutaria 1757 de 2015, esta ley tiene como objeto promover, proteger y garantizar modalidades del derecho a participar en la vida política, administrativa, económica, social y cultural, y así mismo a controlar o vigilar el ejercicio del poder político. Esta ley abarca tres grandes aspectos: los mecanismos de participación ciudadana, la rendición pública de cuentas, el control social a lo público y la coordinación para la participación ciudadana; cuenta con 113 artículos que incluyen obligaciones del Estado, derechos de participación, derechos y responsabilidades de los 
ciudadanos en su ejercicio de participación, además de crear un fondo, premios e incentivos para su desarrollo ${ }^{12}$.

En esta misma dinámica de participación y control social es relevante mencionar que el reciente acuerdo de paz logrado entre el Gobierno de Colombia y la guerrilla de las FARC-EP en el año 2016, incluyó la participación política como segundo punto de la agenda de negociación para la terminación del conflicto armado interno. Para interés de esta investigación, vale la pena resaltar que el Numeral 2 del documento final referido al Acuerdo de Apertura democrática para la Paz, establece el compromiso con el fortalecimiento de la participación ciudadana e "incluye el fortalecimiento de las organizaciones y movimientos sociales, y el robustecimiento de los espacios de participación para que ese ejercicio de participación ciudadana tenga incidencia y sea efectivo, y para que vigorice y complemente la democracia". (Oficina del Alto Comisionado para la paz, p.35)

En síntesis, como se presenta en la figura número 1, los momentos más relevantes para la planeación participativa en Colombia surgen con fuerza desde la Constitución Política de 1991 y en la actualidad han permeado planes de desarrollo de carácter nacional que, por efecto cascada, han orientado también los planes de desarrollo departamentales y municipales.

\footnotetext{
${ }^{12}$ Ley del ministerio del interior con un completo articulado que sienta bases para los ejercicios de participación ciudadana en el país, vale la pena revisar la versión comprimida por Mininterior en http://viva.org.co/PDT_para_la_Construccion_de_Paz/Participacion_democratica/1.\%20Democracia,\%20part icipaci\%C3\%B3n,\%20acci\%C3\%B3n\%20comunal.pdf
} 
Figura 1 Momentos más relevantes para la planeación participativa en Colombia

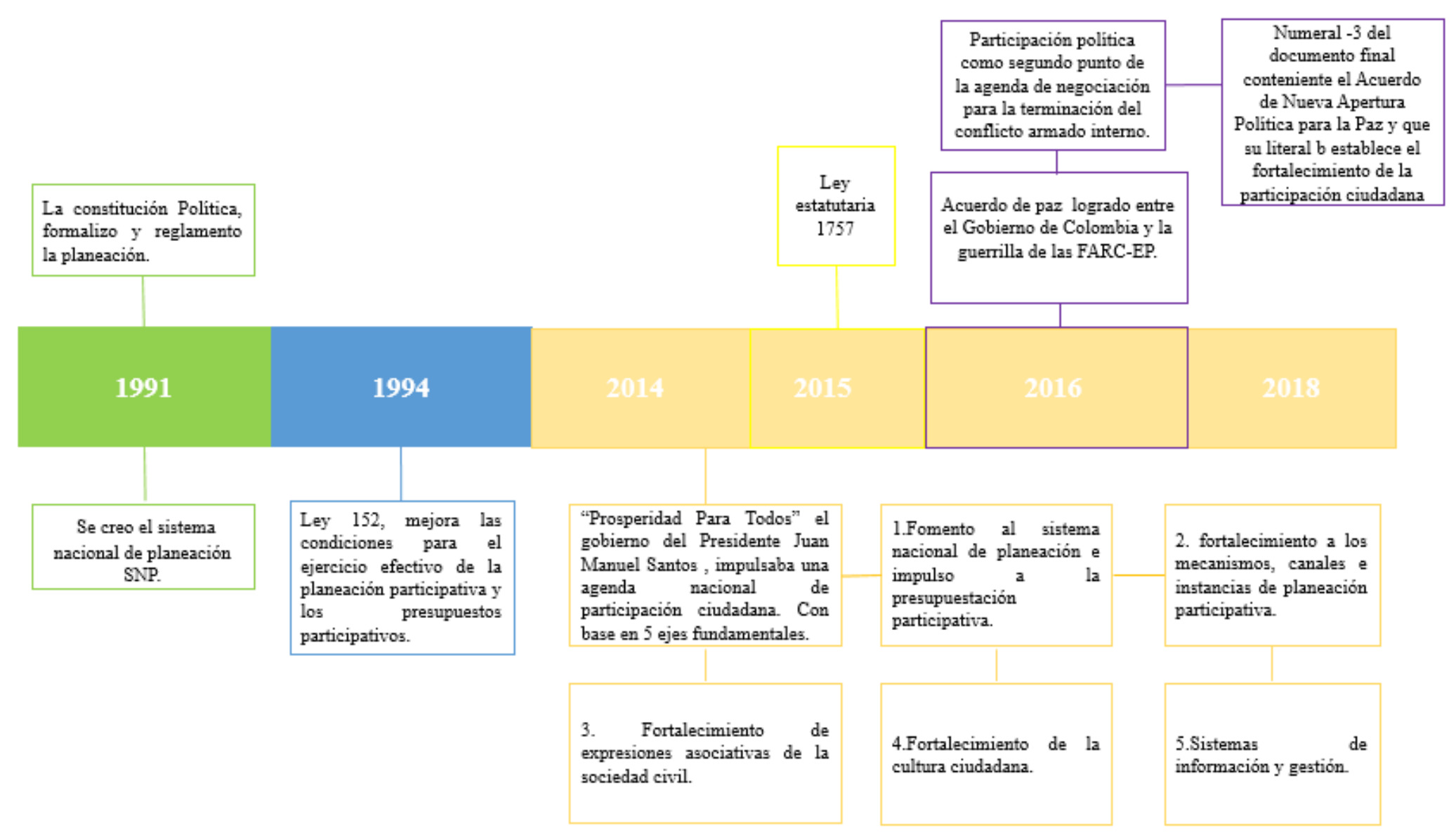

Fuente: Elaboración propia 2017 
En la opinión de diferentes autores, la normatividad hasta ahora existente en Colombia presenta contradicciones internas y representa conflictos respecto a los alcances y la aplicabilidad de la misma, “ aunque para muchos la dinámica normativa inaugura una cultura de la planeación más definida, otros la consideran, desde su origen, un asunto retórico, limitado, exiguo, incompleto y desfasado de las demandas exigidas por la realidad, situación que va en detrimento de su pretensión: el desarrollo" (Tamayo \& Sánchez, 2008, p.18). Este panorama se hace más complejo con los acuerdos logrados en la negociación de paz reciente pues, como se ha expuesto, exige la profundización de los mecanismos e instancias de participación ciudadana, en medio de un contexto normativo adverso, dadas las contradicciones y conflictos vigentes.

El estudio de las contradicciones y los conflictos normativos vigentes escapa al alcance de este texto, pero vale la pena señalar, a manera de ejemplo, cómo en varias de las publicaciones del portal razonpublica. $\operatorname{com}^{13}$ se ha dado un debate sobre cómo esta participación ciudadana contribuye al proceso de paz, quiénes deben participar, cómo funcionarán de manera adecuada esos mecanismos de participación y, en el tema específico de los proyectos minero energéticos y su relación con la participación ciudadana, existen conflictos entre el ordenamiento territorial, las competencias de los entes territoriales y los

13 Dos décadas de participación ciudadana: la Ley 134 de 1994 al banquillo - tomado de: http://www.razonpublica.com/index.php/politica-y-gobierno-temas-27/7386-dos-d\%C3\%A9cadas-departicipaci\%C3\%B3n-ciudadana-la-ley-134-de-1994-al-banquillo.html

¿Será verdad que la participación ciudadana garantiza que la paz sea duradera? - tomado de: http://www.razonpublica.com/index.php/lectura-p\%C3\%BAblica/10218-ser\%C3\%A1-verdad-que-laparticipaci\%C3\%B3n-ciudadana-garantiza-que-la-paz-sea-duradera.html

La participación política en el nuevo Acuerdo de Paz - tomado de http://www.razonpublica.com/index.php/conflicto-drogas-y-paz-temas-30/9878-la-participaci\%C3\%B3npol\%C3\%ADtica-en-el-nuevo-acuerdo-de-paz.html

El acuerdo sobre participación política: ¿cómo será el proceso de apertura democrática? - tomado de http://www.razonpublica.com/index.php/politica-y-gobierno-temas-27/9557-el-acuerdo-sobreparticipaci\%C3\%B3n-pol\%C3\%ADtica-\%C2\%BFc\%C3\%B3mo-ser\%C3\%A1-el-proceso-de-aperturademocr\%C3\%A1tica.html 
mecanismos de participación ciudadana. Frente a este último tema de participación ciudadana en las decisiones minero-energéticas, Gonzales (2016) afirma que "el atractivo de los altos ingresos que genera el sector para el gobierno se ha impuesto sobre la retórica de la democracia participativa", declaración que sintetiza uno de los conflictos vigentes respecto al panorama complejo del contexto normativo e institucional de las políticas públicas de desarrollo en el país.

\section{El proceso de Política Pública: problema, agenda y formulación participativa}

En América Latina, desde la última década del siglo XX con ocasión de las reformas políticas neoliberales, el discurso "modernizador" adoptó el concepto de política pública desde una visión tecnocrática (Roth, 2017 p.69). En medio de debilidades para la elaboración de estudios sociales que funcionaran como apoyo a los gobiernos en la toma de decisiones públicas.

En Colombia, la profundización de los mecanismos e instancias de planeación y participación presentan retos analíticos y prácticos en el campo de las políticas públicas y este debe ser asumido con celeridad por diferentes actores, académicos, políticos y sociales; más aún de cara a los compromisos adquiridos por el Estado y la sociedad en el proceso de paz reciente, que incluye, como se explicó anteriormente, un apartado específico sobre profundización de la democracia y fortalecimiento de la participación política y ciudadana.

En el campo específico de las políticas públicas, los análisis del ciclo vital de las mismas suelen recurrir al dispositivo analítico de la división en fases o etapas (Lasswel \& 
McDougal 1992), pues facilita los análisis por etapas para luego articularlos; estas fases, desde la perspectiva clásica como la describen Meny \& Thoenig (1992), son identificables cinco (5) etapas: 1) identificación de un problema, 2) formulación de decisiones o acciones, 3) toma de decisión, 4) implementación y 5) evaluación.

Este dispositivo analítico que divide el proceso de políticas públicas en etapas, fue adoptado en este estudio para observar la interacción entre sociedad y gobierno en el proceso que tuvo como propósito central posicionar el tema de la empleabilidad y el emprendimiento en la agenda política local en el marco de la formulación de una política pública, a partir de la identificación y priorización participativa de problemáticas y la proposición de soluciones desde abajo hacia arriba, es decir, aborda la fases 1 y 2 del ciclo de política.

\subsection{Del problema a la agenda política}

Las aproximaciones en relación a los problemas públicos, su definición y los factores de inclusión en la agenda política son numerosos, sin embargo, en este apartado se mencionan algunos enfoques, modelos y aproximaciones de diferentes autores con los que es posible abordar el caso estudiado de formulación participativa de política pública en el municipio de San Martín; de este modo, es posible contrastar algunas investigaciones y sus hallazgos con el proceso de formulación de la política pública de empleo y emprendimiento en dicho municipio. 
Para comenzar, es posible afirmar que una situación problema implica inconformidad, malestar o incomodidad en las personas y las comunidades, o en un sector o conjunto de actores pero, no por esto se puede considerar un problema público; para que sea público es necesario que afecte a varias personas, actores o sectores, que sea visible y pueda crecer o permanecer en el tiempo, y es por ello que quienes se ven afectados buscan espacios, mecanismos y ayudas para hacer visible el problema, a través de los medios de comunicación formales y no formales, que hacen que el problema sea reconocido ante la luz pública convirtiéndose así en un problema que adquiere el carácter público. Así, el reconocimiento de un problema público implica que una situación indeseada para la comunidad debe en un principio ser caracterizada y analizada de manera que alrededor del tema surjan análisis, discusiones e investigaciones (Cefai \& terzi 2012).

Cuando el problema es público no está inmerso de manera inmediata en la agenda política y aunque llegara a estarlo, no todos los problemas públicos son incluidos allí; en esta dinámica de acceso y exclusión de problemas públicos en la agenda política, es posible identificar dos factores generales de incidencia: el primero como lo propone Lenoir (1986) obedece a esa posición social ocupada por los grupos promotores, tales como el acceso a recursos políticos, económicos y sociales, el segundo, por su parte lo explican Casar \& Maldonado (2010) tiene que ver con la disposición institucional de acceso o exclusión que obedece al régimen político.

Por otra parte, para Cobb y Elder (1972) existen tres factores que insertan un problema público en la agenda política: el primero tiene que ver con las competencias de la autoridad pública; el segundo está relacionado con la brecha entre "lo que es" y "lo que debería ser”, es decir, la racionalidad más común y coherente, mientras que el tercero tiene 
que ver con la claridad con que se exprese el problema de manera que pueda ser comprensible para cualquier persona.

Chevallier (1986) propone dos factores o fuentes, la primera es externa al Estado y la denomina "demanda" y la otra es interna al Estado y a sus instituciones y la denomina “oferta". Dentro de la denominada demanda identifica tres (3) actores, cada uno con una posición y rol definidos: a) los partidos políticos y los gremios, b) los mediadores sociales y c) los funcionaros públicos, aunque estos últimos pertenecen a la oferta, Chevallier identificó que también pueden hacer parte de la demanda en lo que interpreta como un “camino invertido" de inscripción de problemas en la agenda política.

Otros factores que inciden en dicha inscripción los presenta Garraud (1999) quien identifica un conjunto de actores y su rol según cinco (5) modelos: a) el de la movilización, que tiene elementos de movilización social y mediatización que amplía la audiencia y la atención al problema postulado y proviene desde la base; b) el de la oferta pública, que proviene de organizaciones políticas con propuestas que buscan ganar apoyo y debilitar al gobierno, propósito para el cual emplean medios de comunicación y ampliación del debate político con espectadores sociales; c) el de la mediatización, que proviene desde medios de comunicación, no siempre cuenta con demandas sociales y su momento de visibilidad está altamente ligado a la búsqueda de rating; d) el de la anticipación, que proviene de las autoridades públicas y surge de la identificación temprana de una situación que es o será un problema de interés público, y e) el de la acción corporativista silenciosa, que proviene de grupos organizados y de poder que pueden permear con su influencia las agendas políticas.

En el tercer apartado se aplican algunos elementos de estos modelos al análisis evaluativo del proceso de formulación de política pública desarrollado en San Martín, en 
relación con la transformación de la problemática de empleo en un problema de interés público frente al que, además, se pretende influenciar su inscripción en la agenda política mediante el proceso de formulación participativa.

\subsection{Políticas Públicas participativas}

La participación ciudadana en los procesos de formulación, implementación y seguimiento de políticas públicas representa una condición para aumentar las posibilidades de una gobernanza democrática efectiva. Cunill (1997) define esta participación como el escenario en el cual los ciudadanos se involucran de manera directa en acciones públicas, teniendo una amplia concepción de lo político, espacio en donde tienen los ciudadanos contacto con el estado y aunando opiniones definen metas colectivas y formas que permitan alcanzarlas".

Esta participación, según Ziccardi (1998) podría ser clasificada como institucionalizada o autónoma, según esté contenida en el marco legal y normativo o, por el contrario, organizada desde las propias bases de la sociedad. Esta misma autora identifica que la participación ciudadana cuenta con tres funciones: otorgar legitimidad al gobierno; promover una cultura democrática; hacer más eficaces la decisión y la gestión públicas. Con estas características puede llegar a constituir un mecanismo para el empoderamiento social.

Desde la perspectiva de la gobernanza, es importante que la participación ciudadana involucre a los individuos en el espacio público estatal y no estatal desde su identidad de 
ciudadanos, es decir, como integrantes de una comunidad política. En Colombia, la apuesta constitucional por la democracia participativa que extiende el derecho de participar a todos los actores y ciudadanos para decidir con libertad sobre su vida individual y las decisiones colectivas exige, como en otros casos, el ejercicio de gobiernos igualmente democráticos. Como menciona Bobbio (1989) la democracia puede entenderse como forma de gobierno en la que los ciudadanos tienen lugar en el ejercicio del poder político, sin embargo el ejercicio de planeación participativa exige ir más allá, hasta formas de gobernanza que dentro del sistema democrático, favorezca tanto la coordinación como la confrontación política entre actores políticos, sociales y económicos, favoreciendo así la construcción de consensos, incluso consensos que puedan ser conflictivos.

Manteniendo esta dirección, para Aguilar (2009) la política pública reúne en el conjunto de acciones que tiene como interés y causa el bienestar colectivo, la interlocución y el dialogo que ha surgido entre el gobierno y los sectores de la ciudadanía, haciendo asi según Uvalle, (2005) que lo público de las políticas se origine de la forma en que la ciudadanía participa de manera activa en las etapas de formulación, implementación y seguimiento. Es así que la participación ciudadana es un proceso que proporciona a los individuos la oportunidad de influir en las decisiones públicas por ello para Cogan \& Sharpe (1986) este ha sido un componente imprescindible del proceso democrático en la toma de decisiones.

Concuerdan Chac M, \& Villareal 2004, 2009 que, durante este proceso, se le concede a la ciudadanía la posibilidad de expresar razones y de llegar a acuerdos con otros actores, teniendo la oportunidad para deliberar y concertar, e incluso expresar los desacuerdos en el conflicto político; para un ben resultado son necesarias la capacidad argumentativa y la capacidad negociadora. Esta participación depende y está vinculada a 
los modelos de democracia y al tipo de relación gobierno-sociedad que se ha construido o se quiere construir.

Así mismo, la participación ciudadana permite que los ciudadanos se involucren en una amplia gama de actividades de formulación de políticas, incluida la determinación de los niveles de servicio, las prioridades presupuestarias y la aceptabilidad de los proyectos para orientar los programas gubernamentales hacia las necesidades de la comunidad. De esta manera, la ciudadanía puede aumentar su influencia en las políticas y programas públicos de modo que aseguren un impacto más positivo en su vida individual y colectiva, social y económica. (UN Public Administration Programme).

\section{El proceso de formulación de la política pública de empleo y emprendimiento en San Martín, Cesar}

Para analizar el proceso de formulación de política pública mencionado, se hace necesario ofrecer una contextualización del territorio abordando componentes poblacionales y sectoriales, que permitan describir la situación actual, así como comprender la pertinencia del proceso de formulación de la política específica. Para comenzar, es necesario reconocer la crisis de legitimidad social de la operación petrolera en el municipio; tal y como se presenta en la figura número 2 que reúne en una línea de tiempo las principales noticias en prensa digital sobre el fracking en San Martín, entre abril de 2016 y junio de 2017, es evidente que las características de la dinámica actual del municipio en relación con la exploración y explotación de hidrocarburos a través de esta técnica, ha 
despertado el interés no solo de sus habitantes sino también de autoridades nacionales con la intensión de reducir la presión que se está presentando sobre el medio ambiente por parte de las petroleras y en atención a las movilizaciones sociales que demandan la protección de derechos ambientales; dicha situación está generando afectaciones a la comunidad y está perjudicando la productividad y eficiencia de sectores económicos, especialmente el sector de hidrocarburos.

Adicional a estos espacios participativos que se fijaron en el marco del proceso, existieron otras instancias de diálogo formal y no formal para atender a los requerimientos en función de la gestión del empleo en el territorio y temas de carácter ambiental. A nivel institucional quienes lideraron y o coordinaron estos espacios, fueron principalmente entidades que pertenecen a la ETH.

De manera que, aunque la política pública busca atender y dar solución a este tipo de situaciones a largo plazo, en la inmediatez las instituciones responsables otorgaron la atención que requieren los problemas descritos en este apartado. 
Figura 2 Hallazgos de prensa relacionado con el fracking en San Martín, 2016 -2017

\begin{tabular}{|c|c|c|c|}
\hline $\begin{array}{l}\text { "Fracking" genera } \\
\text { incertidumbre en San Martin, } \\
\text { Cesar } \\
\mathbf{1 3} \text { de abril }\end{array}$ & \multirow{3}{*}{$\begin{array}{c}\text { Fracking: en el Cesar bloquean el } \\
\text { primer trabajo de estas caracteristicas } \\
\text { en Colombia } \\
08 \text { de septiembre } \\
\text { sostenibilidad.semana.com }\end{array}$} & $\begin{array}{c}\text { San Martin vuelve a protestar contra la técnica del } \\
\text { 'fracking' } \\
19 \text { de Octubre } \\
\text { elheraldo.co }\end{array}$ & \\
\hline Elespectador.com & & Fuertes protestas contra el fracking en San & \\
\hline \multirow{2}{*}{$\begin{array}{l}\text { Habitantes de San Martin, } \\
\text { Cesar, preocupados por fracking } \\
\text { en su territorio } \\
\mathbf{2 3} \text { de abril } \\
\text { om }\end{array}$} & & $\begin{array}{c}\text { Martin, Cesar } \\
26 \text { de octubre } \\
\text { noticias.caracoltv.com }\end{array}$ & \\
\hline & & $\begin{array}{l}\text { San Martin, el pueblo que rechaza el 'fracking' en } \\
\text { su territorio } \\
27 \text { de octubre } \\
\text { eltiempo.com }\end{array}$ & \\
\hline Abril 2016 & Septiembre 2016 & Octubre 2016 & Marzo 2017 \\
\hline \multirow[t]{3}{*}{$\begin{array}{c}\text { El fracking amenaza a la } \\
\text { comunidad de San Martin, } \\
\text { Cesar } \\
29 \text { de abril } \\
\text { las2orillas.co }\end{array}$} & & $\begin{array}{c}\text { El ESMAD arremete contra los opositores al } \\
\text { fracking en San Martin } \\
19 \text { de octubre } \\
\text { colombiaplural.com }\end{array}$ & \multirow{3}{*}{$\begin{array}{c}\text { Tribunal admite primera acción } \\
\text { popular por impactos del } \\
\text { fracking en San Martin (Cesar) } \\
03 \text { de marzo } \\
\text { caracol.com.co }\end{array}$} \\
\hline & & $\begin{array}{c}\text { San Martin vuelve a protestar contra la técnica del } \\
\text { 'fracking' } \\
19 \text { de octubre } \\
\text { elheraldo.co }\end{array}$ & \\
\hline & & $\begin{array}{c}\text { Claudia López solicitó una mesa de diálogo sobre } \\
\text { el Fracking en San Martin } \\
28 \text { de octubre } \\
\text { claudia-lopez.com }\end{array}$ & \\
\hline
\end{tabular}

Fuente: Elaboración propia 2017 


\subsection{Diseño metodológico}

El estudio es un análisis cualitativo de tipo descriptivo con un componente de tipo evaluativo, recurre al análisis de información primaria (apuntes de investigación, noticias, artículos científicos y de expertos.) y secundaria (bases de datos, índices y bibliografías, portales web y cifras estadísticas oficiales) y tuvo como estrategia transversal la observación participante ${ }^{14}$ permitida al investigador por su rol de facilitador en el proceso metodológico desarrollado con los actores, en el cual se recurrió a la estrategia de grupos de discusión, en grupos no mayores a 12 personas ${ }^{15}$. Como los 5 talleres que se describen con mayor detalle en el siguiente capítulo, tuvieron una participación promedio de 50 personas (entre estas líderes comunitarios de la zona rural y urbana, líderes de los productores, empresarios y personas de la comunidad en general adultas y jóvenes), se dividieron y organizaron grupos y fue así que se originaron los análisis en talleres participativos de carácter formal, cuyos documentos memoria fueron analizados a través de la técnica de análisis de contenido temático ${ }^{16}$.

\footnotetext{
14 Marshall Y Rossman (1989) definen la observación como "la descripción sistemática de eventos, comportamientos y artefactos en el escenario social elegido para ser estudiado" (p.79). Las observaciones facultan al observador a describir situaciones existentes usando los cinco sentidos, proporcionando una "fotografía escrita" de la situación en estudio (Erlandson, Harris, Skipper \& Allen 1993). Demunck Y Sobo (1998) describen la observación participante como el primer método usado por los antropólogos al hacer trabajo de campo. El trabajo de campo involucra "mirada activa, una memoria cada vez

mejor, entrevistas informales, escribir notas de campo detalladas, y, tal vez lo más importante, paciencia" (Dewalt \& Dewalt 2002, p.vii). (como se citó en Barbara B. 2006).

15 Algunos autores sitúan el límite superior algo más elevado, considerando que grupos de hasta 12 participantes pueden conducir a resultados adecuados (Bers, 1989; Byers y Wilcox, 1988; Grunig, 1990). (como se citó en flores. J 1993)

${ }^{16}$ El análisis de contenido se basa en la lectura (textual o visual) como instrumento de recogida de información, lectura que a diferencia de la lectura común debe realizarse siguiendo el método científico, es decir, debe ser, sistemática, objetiva, replicable, y valida. Andreu J. Krippendorff (1990, p 28) define el análisis de contenido como "una técnica de investigación destinada a formular, a partir de ciertos datos, inferencias reproducibles y válidas que puedan aplicarse a su contexto".
} 
Dentro de los objetivos el documento en su conjunto 1) analiza el proceso de inclusión de un problema en la agenda política desde las perspectivas de autores en dialogo con las dinámicas presentadas en el municipio de San Martín y describe cómo fue el proceso de formulación participativa de la política pública de empleo y emprendimiento con los diferentes actores. 2) Presenta los resultados y las solicitudes definidas por la comunidad y esas lecciones aprendidas del proceso que podrían replicarse en otros territorios y para otros sectores.

El proceso se desarrolló durante un periodo de análisis de ocho (8) meses; en la fase de alistamiento se identificaron categorías y aproximaciones desde la perspectiva de diferentes autores, con respecto a estas aproximaciones dentro del documento se genera un dialogo entre las perspectivas de la fase de agendamiento público del problema y las características de la formulación de una política pública participativa. Con lo anterior dentro de los talleres participativos los temas de discusión se orientaron con las aproximaciones de diferentes autores.

\subsection{San Martín: de la dependencia petrolera a la discusión sobre el empleo y el emprendimiento}

El municipio de San Martín es uno de los veinticinco (25) municipios que comprenden el departamento ${ }^{17}$ del Cesar; se ubica en la parte sur del mismo y físicamente lo distancian de Valledupar, capital del departamento, $342 \mathrm{~km}$ de recorrido terrestre, esta

\footnotetext{
${ }^{17}$ Cesar cuenta con una extensión territorial de $22.905 \mathrm{kms} 2$, que equivalen al $2 \%$ del territorio nacional y al $15 \%$ del Caribe Colombiano
} 
distancia hace que San Martin desarrolle sus relaciones más cercanas con la ciudad de Bucaramanga, capital del vecino departamento de Santander, debido a la distancia de $129 \mathrm{~km}$.

Figura 3 Ubicación de San Martín en el departamento del Cesar y el País

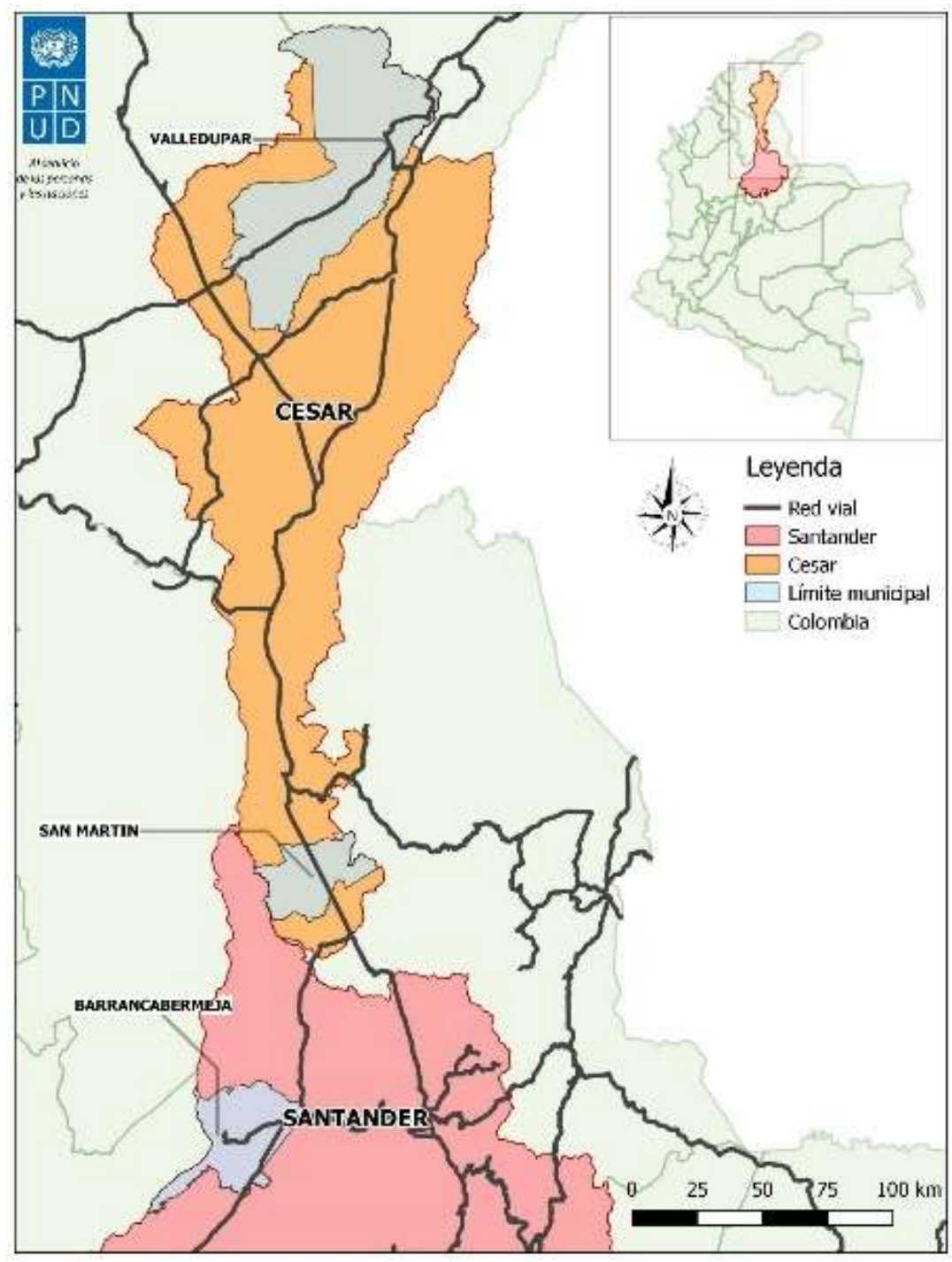

Fuente: PNUD 2017

El municipio cuenta con una extensión territorial de $905 \mathrm{Km} 2$ que equivale al 3,7\% del área departamental, distribuido aproximadamente en $5 \mathrm{kms} 2$ de área urbana en donde se 
encuentran veintitrés (23) Barrios y $900 \mathrm{Km} 2$ en el resto de área territorial integrada por 9 corregimientos y treinta y dos (32) veredas.

Con respecto a la población que habita en el territorio, las cifras proyectadas con base en el Censo realizado en el año 2005 por el Departamento Administrativo Nacional de Estadística (DANE), establecen que la población del municipio para el año 2016 es de 18.650 personas, compuesta en un $51,05 \%$ por hombres y un $48,95 \%$ por mujeres. Con una densidad poblacional de 21,74 personas por $\mathrm{Km} 2$ y una tasa de crecimiento del 1,2\%, las personas se encuentran distribuidas en el territorio por poco de manera igualitaria con un $48,9 \%$ que habita en la cabecera urbana y un 51,1\% en el resto del territorio municipal.

Figura 4 Pirámide poblacional de San Martín - Cesar 2012* - 2016* -2020*

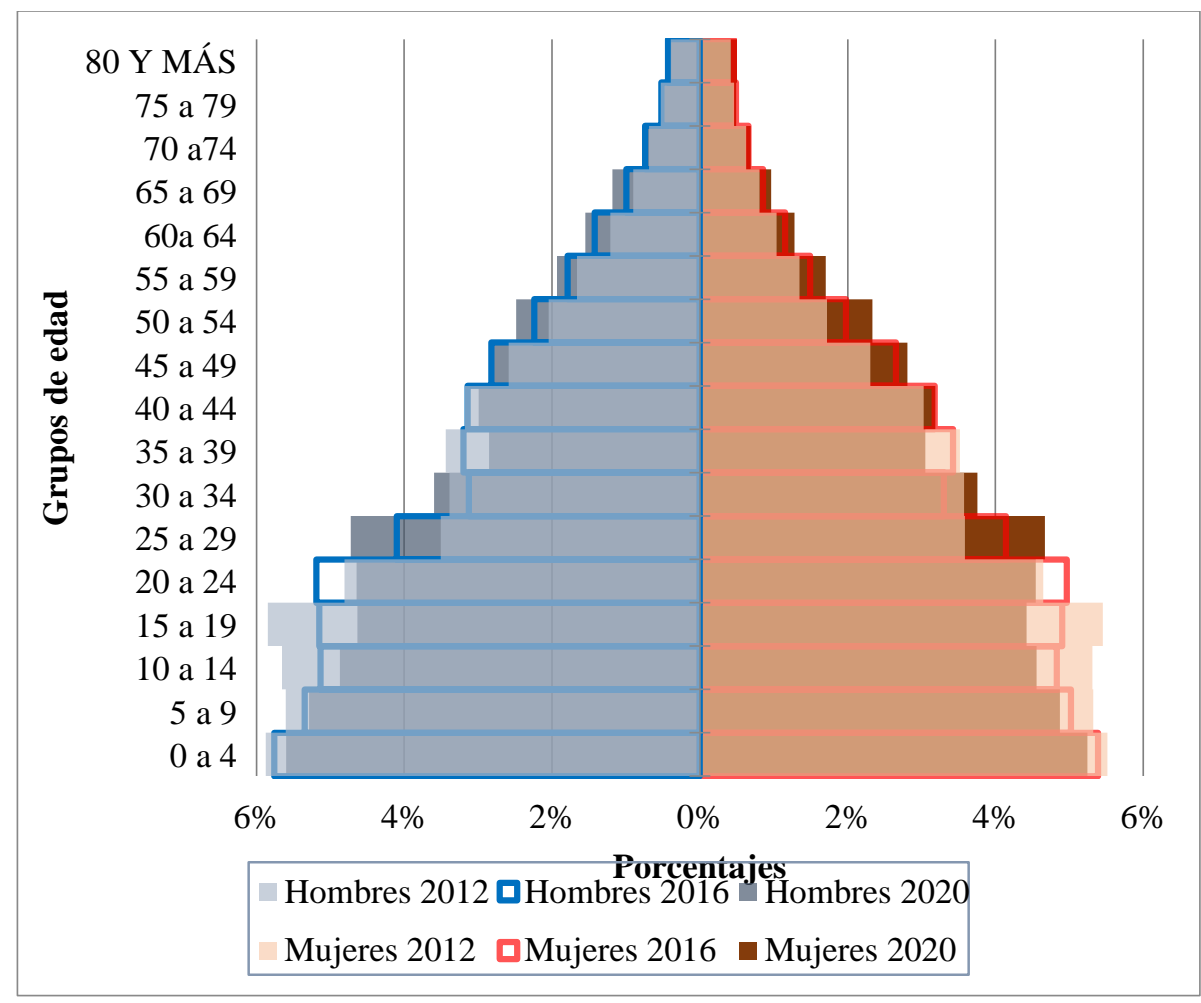

Fuente: Elaboración propia con base en proyecciones del DANE 2017

*Años proyectados 
La dinámica que se refleja en la pirámide poblacional de la figura 4, implica que la población en edad de trabajar, $\mathrm{PET}^{18}$, ha venido aumentando desde 2012. El paso de 13.357 en 2012 a 14.291 PET en 2020, implica un aumento de 6,42\% en la oferta potencial de fuerza laboral en San Martín. Para el año 2016, la PET es de 14.272 personas, que representa un $76,53 \%$ del total de la población que habita en el municipio. El restante 18,2\% de la población lo integran las personas menores de 12 años.

Para tener una mejor visión de la relevancia de la política pública de empleo y emprendimiento es necesario revisar el sistema general de seguridad: aunque el municipio de San Martín cuenta con una población proyectada por el DANE a 2016 de 18.650 habitantes, según la afiliación al sistema de salud esta población varía a 19.830 usuarios lo que representa un $6,3 \%$ adicional. La cobertura del régimen subsidiado ${ }^{19}$ para febrero es de 2016 de 14.838 usuarios; la población del régimen contributivo ${ }^{20}$ alcanza un total de 4.710 usuarios con capacidad de pago; mientras que la población con excepción del régimen alcanza la cifra de 282 usuarios. La diferencia de cifras poblacionales se puede explicar, entre otros casos, debido a la constante población flotante que viene de municipios aledaños y del resto del país.

Las cifras de afiliación al sistema de salud implican que el 74,83\% de la población pertenece al régimen subsidiado, el 23,75 al régimen contributivo y el 1,42\% a la población

\footnotetext{
${ }^{18}$ Según el DANE, este segmento está constituido por las personas de 12 años con mayoría en las zonas urbanas y de 22 años y más personas en las zonas rurales. Se dividen en población económicamente activa y población económicamente inactiva.

${ }^{19}$ El Régimen Subsidiado es el mecanismo mediante el cual la población más pobre del país, sin capacidad de pago, tiene acceso a los servicios de salud a través de un subsidio que ofrece el Estado. (MinSalud) Tomado de : https://www.minsalud.gov.co/salud/Paginas/R\%C3\%A9gimenSubsidiado.aspx

${ }^{20}$ Es un conjunto de normas que rigen la vinculación de los individuos y las familias al Sistema General de Seguridad Social en Salud, cuando tal vinculación se hace a través del pago de una cotización, individual y familiar, o un aporte económico previo financiado directamente por el afiliado o en concurrencia entre éste y su empleador. (MinSalud) Tomado de: https://www.minsalud.gov.co/proteccionsocial/Regimencontributivo/Paginas/regimen-contributivo.aspx
} 
con excepción del régimen, si dentro del análisis no se contempla la población flotante que en gran parte está siendo contribuyente dentro del régimen (en el caso de los funcionarios de las petroleras) la población que pertenece al municipio tendría mayor participación dentro del régimen subsidiado, lo que implica una alta tasa de informalidad y desempleo.

Para complementar estas características poblacionales y de empleabilidad es necesario ahondar en la composición del tejido productivo para el 2013 según cifras del Departamento Nacional de Planeación DNP, en el territorio se evidencia una alta dependencia del sector hidrocarburos, tal y como se observa en la siguiente figura:

Figura 5 Valor agregado municipal 2013

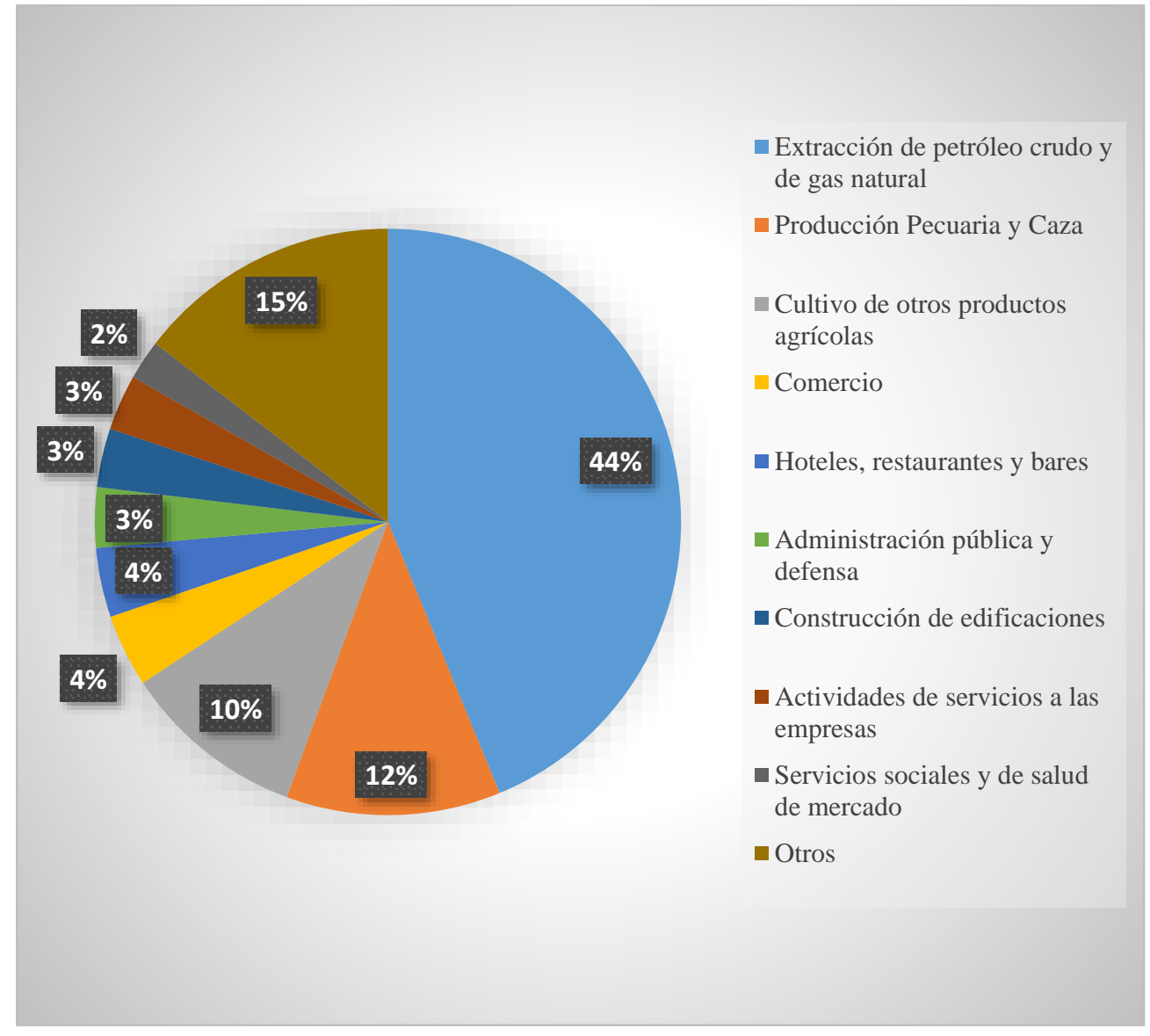

Fuente: Ficha Web Municipal DNP 2015 
El sector extractivo de petróleo y gas natural representa el $44 \%$ del total de la producción del municipio, seguido se encuentran la producción pecuaria y la caza con un $12 \%$ y en un tercer lugar la producción de cultivos y otros productos agrícolas con el $10 \%$. Es evidente que la suma del sector agro-pecuario solo alcanza a representar la mitad del total que representa el sector hidrocarburos y en términos de mayor cantidad de empleo y de seguridad alimentaria esta situación es poco deseable ${ }^{21}$. Sumado a esta situación, el fracking como practica de sector hidrocarburos genera en la comunidad sanmartinense situaciones conflictivas, como se vio en la figura número 2.

Como se evidenció en el marco de los cinco (5) talleres participativos que se reseñarán en el siguiente apartado, en mención de concejales, líderes comunitarios y la comunidad en general, en el aspecto laboral el hecho que la mayor parte de las personas deseen pertenecer a las nóminas de la petroleras, por sus condiciones laborales y salarios elevados genera dinámicas de presión para que se dé la contratación de mano de obra local, asunto que ha generado bloqueos a la producción y paros que obligan a la movilización institucional y conlleva a que los empresarios petroleros obtengan días y semanas de pérdidas económicas y de producción.

Entre los factores que limitan la contratación de todo el personal en la zona de influencia están las características propias de la mano de obra, pues los perfiles ${ }^{22}$ no se ajustan a lo que el sector requiere bien sea por su formación o su experiencia y como se identificó en el taller participativo \#2 para la “definición de problemas, causas y efectos

\footnotetext{
${ }^{21}$ Ya que implica desgaste en materia ambiental y que muchos de los empleos que genera no pueden ser asumidos por personas del municipio por el déficit de capital humano en función de la formación y la experiencia.

${ }^{22}$ Ingenieros de Petróleos, Geólogos y Geofísicos, Ingenieros Electrónicos, Mecánicos y Mecatrónicos, Ingenieros Industriales y Químicos, Cargos administrativos, Soldadores.etc.
} 
sobre el empleo y el emprendimiento" las problemáticas más mencionadas son: la mala gestión de la intermediación laboral, es decir, el poco uso que se da a las plataformas de gestión del empleo, lo que a su vez se relaciona con el limitado acceso a las TIC por parte de la comunidad y con las dificultades que tiene la población para el manejo de dichas plataformas. Por otro lado los contratos laborales que se otorgan por relaciones personales y sin una adecuada gestión han generado incomodidad e inconformidad de la comunidad, aunque desde el Decreto $1668^{23}$ del 2016 se intentó dar claridad a esta gestión del empleo en las áreas de influencia petrolera dada aprobación, las entidades y organismos pertinentes aún se encuentran en proceso de socialización de los lineamientos de dicho decreto con entidades públicas y empresas privadas para su correcta implementación.

En términos de las problemáticas económicas, aunque se han abordado en medio de los problemas laborales y sociales, como se identificó en el taller referido, estos obedecen a la falta de interés por otras actividades económicas, no solo desde las personas sino desde las instituciones públicas y los empresarios; de hecho los pocos empresarios que se han decidido a apostarle a otros sectores de la economía, enfrentan dificultades para conseguir personas interesadas en laborar ya que en estos obtienen ingresos más bajos. Por otra parte, cuando la situación del sector hidrocarburos no es favorable y no hay contratación pero sí despidos las actividades conexas de bienes y servicios alrededor del sector también se ven directamente afectadas.

\footnotetext{
${ }^{23}$ Los porcentajes de contratación en el área de influencia son del 100\% de mano de obra no calificada y por lo menos el $30 \%$ de calificada de be ser residente en el área de influencia. Las actividades de exploración y explotación deben incluir cláusulas sobre la gestión del servicio público de empleo SPE en obligación con las disposiciones previstas en el decreto.
} 
También se dan problemáticas ambientales, en torno a la explotación minera y de hidrocarburos en el caso de San Martín es importante considerar que se trata del primer ${ }^{24}$ municipio en Colombia en donde se otorgó licencia para explorar mediante el Fracking ${ }^{25}$, aunque "el proceso de licenciamiento ambiental en la zona no ha superado el requisito de la socialización”, como lo menciona Revista Semana 2015en su sección de sostenibilidad citando como fuente a Carlos Andrés Santiago vocero de la Corporación Defensora del Agua, Territorio y Ecosistemas ${ }^{26}$ (Cordatec).

Sin entrar acá en el juicio de si es o no una práctica apropiada para el ecosistema y si afecta el agua y demás elementos de sistemas ecológicos, las experiencias del país y el mundo sí consideran que las prácticas de exploración y explotación carbonífera y de hidrocarburos genera implicaciones de tipo ambiental e impactos muchas veces irreversibles y no mitigables.

Con este esbozo de la situación actual del territorio, las presiones de la comunidad en relación con las dinámicas humanas, económicas, sociales y ambientales se presenta a continuación cómo desde el proceso de formulación de la política pública de empleo y emprendimiento, se identificaron con claridad y detalle las problemáticas y se abordaron en las líneas de acción alternativas de solución que quedaron enmarcadas en la propuesta del documento de acuerdo que el PNUD construyó junto con la comunidad, para que la alcaldía municipal cuente con esta valoración, para su consideración y futura implementación

$24 \mathrm{http} / / /$ sostenibilidad.semana.com/medio-ambiente/articulo/fracking-en-colombia-amenazan-a-opositoresdel-primer-proyecto-en-el-pais/36060

25 "La fractura hidráulica (fracking) es una técnica de extracción de hidrocarburos no convencionales como el petróleo y el gas, que de otra manera serían imposibles de extraer. En el principio de los años 2.000, las compañías de energía comenzaron combinando la perforación horizontal con la fractura hidráulica para la extracción de estos recursos. El proceso implica la perforación horizontal a través de una capa de roca y la inyección de una mezcla presurizada de agua, arena, y otros productos químicos en las fracturas de la roca y facilita el flujo de petróleo y de gas." Escuela Forestal y de Estudios Ambientales de la Universidad de Yale" ${ }^{26}$ Agremiación que se opone a la exploración y extracción de petróleo a través de fracking. 


\subsection{Descripción de la metodología del proceso de formulación de política}

Este ejercicio de formulación de política pública de empleo y emprendiendo tuvo como marco metodológico transversal las directrices ofrecidas por Ministerio del Trabajo

de Colombia en función del trabajo decente ${ }^{27}$, como lo son los pactos y pilares del trabajo decente: Erradicación del trabajo infantil, por el empleo como servicio público, por la calidad del trabajo y las empresas productivas, por la formalización del traba y por la protección a la vejez. Contando con la transversalidad del diálogo Social por la equidad y la paz como pilares del Trabajo Decente.

Pactos y pilares que se articulan con los cuatro componentes definidos por la organización internacional del Trabajo OIT: Crear empleos y ocupaciones decentes; garantizar los derechos fundamentales en el trabajo; extender la protección y seguridad social y reforzar el tripartidismo y el diálogo social que se encuentran en el proyecto decreto de ley de $2017^{28}$.

\footnotetext{
${ }^{27}$ resume las aspiraciones de la gente durante su vida laboral, significa contar con oportunidades de un trabajo que sea productivo y que produzca un ingreso digno, seguridad en el lugar de trabajo y protección social para las familias, mejores perspectivas de desarrollo personal e integración a la sociedad, libertad para que la gente exprese sus opiniones, organización y participación en las decisiones que afectan sus vidas, e igualdad de oportunidad y trato para todas las mujeres y hombres. Este concepto reconoce el trabajo como fuente de dignidad personal, estabilidad familiar, paz en la comunidad.

28 Tomado

de http://www.mintrabajo.gov.co/documents/20147/6028064/PROYECTO+DECRETO+TRABAJO+DECENTE .pdf/f25d8529-e005-2a6b-acdb-fc83b6d352ad?version=1.0
} 
Figura 6 Síntesis momentos de formulación

\begin{tabular}{|l|} 
Socialización \\
\begin{tabular}{|l|}
\hline Un primer momento de diálogo se \\
dio entre el PNUD y la autoridad \\
local, presentando de igual manera \\
el plan de trabajo, las \\
metodologías de recolección y \\
análisis de información y los \\
momentos de trabajo con la \\
comunidad. \\
\hline
\end{tabular}
\end{tabular}

Análisis de información
\begin{tabular}{|lr|}
$\begin{array}{l}\text { Un segundo momento, } \\
\text { previo al trabajo de campo, } \\
\text { fue el análisis de la } \\
\text { información recundaria } \\
\text { emitida por entidades de } \\
\text { carácter r r nacional, } \\
\text { departamental y municipal. }\end{array}$ \\
\hline
\end{tabular}

\section{Perfiles}

vocacionales grado 10 y 11

\section{Priorización}

Un tercer momento, se llevo a cabo el taller \#1 con expertos sectoriales, con el fin de priorizar sectores económicos y productivos alternativos al sector hidrocarburos.

\section{Taller \#1}

\section{Socialización parcial Comunidad}

\section{Socialización parcial Concejo municipal}

Definición de líneas

\begin{tabular}{|l|}
\hline \multicolumn{2}{|l|}{ Finalmente en un } \\
noveno momento, fue \\
desarrollado el taller \#5 \\
para la "socialización \\
de líneas estratégicas \\
de la política pública de \\
empleo \\
emprendimiento". \\
\end{tabular}

Taller \#5

$$
\begin{aligned}
& \text { En un octavo momento } \\
& \text { lo identificado en los } \\
& \text { talleres y en el trabajo de } \\
& \text { campo, así como la } \\
& \text { caracterización del } \\
& \text { territorio, } \\
& \text { problemáticas y las } \\
& \text { líneas estratégica del } \\
& \text { plan de acción fue } \\
& \text { socializada con } \\
& \text { concejales del cabildo } \\
& \text { municipal. }
\end{aligned}
$$

\begin{tabular}{|c|}
\hline $\begin{array}{l}\text { En un séptimo } \\
\text { momento, el } 24 \text { de } \\
\text { febrero de 2017, fue } \\
\text { desarrollado el taller \#4 } \\
\text { para la "definición de } \\
\text { líneas estratégicas de la } \\
\text { política pública de } \\
\text { empleo } \\
\text { emprendimiento". }\end{array}$ \\
\hline
\end{tabular}

Fuente: Elaboración propia 2017 estratégicas

\section{Identificación problemáticas}

Taller \#4
Taller \#3

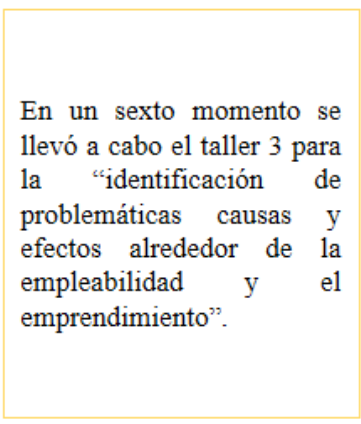

En un cuarto momento se realizó un encuentro con setecientos noventa (790) estudiantes de grado $10^{\circ}$ y $11^{\circ}$ en cinco (5) instituciones educativas, en los corregimientos de Minas, La curva, Terraplén y en la cabecera municipal.

\section{Caracterización cadenas de valor}

En un quinto momento
del proceso estudiado
estuvo destinado al taller
$\# 2 \quad$ para la
"caracterización de las
cadenas de valor de los
sectores priorizados". r

Taller \#2 
En los enfoques trasversales el ejercicio tuvo como objeto identificar y potenciar sectores productivos alternativos a los hidrocarburos, no con el fin de generar una reconversión laboral y productiva inmediata sino de fomentar procesos productivos con una visión que contemple un futuro sin hidrocarburos y que mientras tanto, propenda para que los beneficios de esta industria se traduzcan en mejores condiciones de productividad y competitividad para otros productos y sectores, evitando así la paradoja de la abundancia ${ }^{29}$.

En esta lógica y dirección, para dar inicio al proceso se realizó una primera reunión de socialización con representantes de la Estrategia Territorial para la gestión equitativa y sostenible del sector Hidrocarburos (ETH), con el objetivo de conocer el plan de trabajo propuesto por el proyecto de Desarrollo y Mercado Laboral (DML) del PNUD, programa que lleva a cabo esta acción demostrativa definida para la construcción participativa de acuerdos en torno al empleo y el emprendimiento, para que posteriormente sean adoptados como políticas públicas por las autoridades locales.

Un segundo momento de diálogo se dio entre el PNUD y la autoridad local, presentando de igual manera el plan de trabajo, las metodologías de recolección y análisis de información y los momentos de trabajo con la comunidad, para lo cual se solicitó su acompañamiento y representatividad, así como espacios y equipos de proyección para los talleres, datos de líderes comunitarios y de representantes de los sectores productivos para facilitar las convocatorias.

\footnotetext{
29 "los países ricos en recursos naturales, cuya economía se sustenta prioritariamente en su extracción y exportación, encuentran mayores dificultades para desarrollarse. Sobre todo parecen estar condenados al subdesarrollo aquellos que disponen de una sustancial dotación de uno o unos pocos productos primarios. Estos países estarían atrapados en una lógica perversa conocida en la literatura especializada como "la paradoja de la abundancia", "la maldición de la abundancia de recursos naturales", o simplemente, como la define Joseph Stiglitz (2006), "la maldición de los recursos". Tomado de LA MALDICIÓN DE LA ABUNDANCIA Alberto Acosta 2009
} 
Un tercer momento, previo al trabajo de campo, fue el análisis de la información secundaria emitida por entidades de carácter nacional, diligenciando una matriz de priorización inicial y tentativa de sectores promisorios o con potencial de crecimiento. Para este proceso de identificación y selección de actividades económicas, se combinaron dos metodologías complementarias: priorización cuantitativa y priorización cualitativa.

En la priorización cuantitativa se identificaron los sectores potenciales del municipio, a través de la revisión de un conjunto de variables tales como los rendimientos productivos, las hectáreas sembradas y cosechadas, estadísticas que permitieron una aproximación al impacto económico e importancia de los sectores económicos. En la priorización cuantitativa se tomó información de fuentes secundarias como Agronet $^{30}$ y el Plan de Desarrollo Municipal 2016 - 2019 "Juntos podemos", seguidamente se estableció un puntaje para los sectores económicos y a partir de éste se identificaron los sectores económicos con potencial de crecimiento en el municipio.

En la priorización cualitativa se contempló la agenda pública y política en relación con la promoción y los intereses de los diferentes planes y programas que tuvieran relación con el sector, esto permitió evaluar en parte la prospectiva del sector y las posibilidades de competir en mercados nacionales e internacionales, así como también las posibilidades de acceder a financiamiento y potenciamiento de los sectores.

Los criterios de la priorización cuantitativa y cualitativa fueron los siguientes:

\footnotetext{
${ }^{30}$ Red de información y Comunicación del Sector Agropecuario Colombiano.
} 
Tabla 1 Criterios de priorización de sectores potenciales económicamente

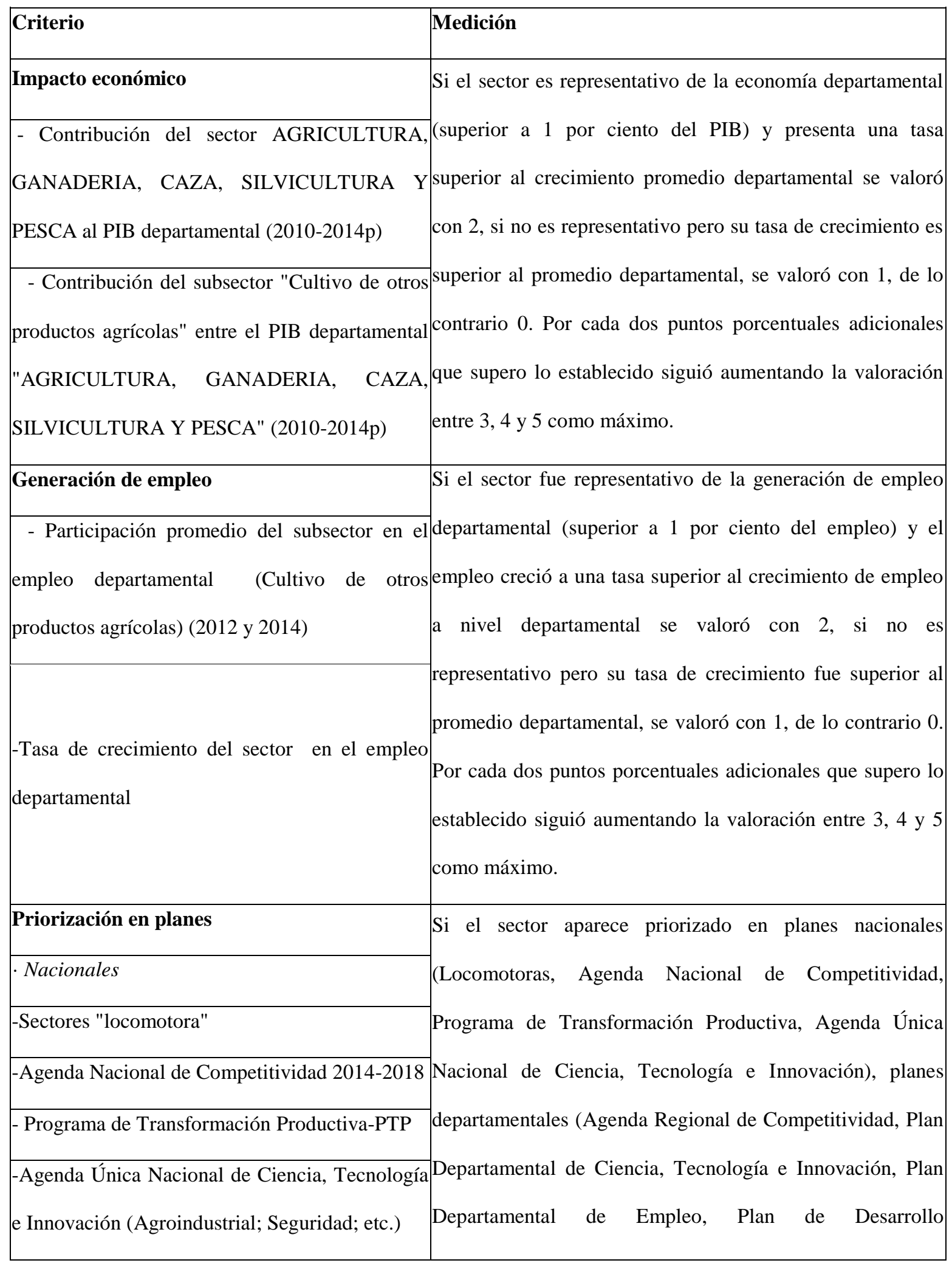




\begin{tabular}{|c|c|}
\hline Criterio & Medición \\
\hline Departamentales & Departamental, Plan Estratégico Sectorial) y planes \\
\hline $\begin{array}{l}\text {-Agenda interna para la productividad y la } \\
\text { Competitividad }\end{array}$ & $\begin{array}{l}\text { municipales (Plan de Desarrollo Municipal, Planes } \\
\text { específicos de fortalecimiento del sector) se valoró con } 1 \text { en }\end{array}$ \\
\hline $\begin{array}{l}\text {-Plan Departamental Ciencia, Tecnología e } \\
\text { Innovación }\end{array}$ & caso de existir el plan referido, en caso contrario 0 . \\
\hline -Plan Departamental de Empleo & \\
\hline -Plan de Desarrollo departamental & \\
\hline $\begin{array}{l}\text {-Plan estratégico sectorial (plan de acción, } \\
\text { clúster, etc.) }\end{array}$ & \\
\hline Municipales & \\
\hline - Plan de desarrollo municipal & \\
\hline Cifras del sector en el municipio & \\
\hline Área sembrada & \\
\hline $\begin{array}{l}\text {-Participación en el total del área agrícola } \\
(2007-2014)\end{array}$ & $\begin{array}{l}\text { Para sectores agrícolas hizo referencia al crecimiento de } \\
\text { hectáreas del cultivo en el municipio, crecimiento de la }\end{array}$ \\
\hline - Variación del área sembrada (2007-2014) & $\begin{array}{l}\text { produccion agricola y crecimiento de la productividad del } \\
\text { cultivo. Para sectores pecuarios hizo referencia al al }\end{array}$ \\
\hline Producción & crecimiento de hectáreas de uso pecuario, número de \\
\hline $\begin{array}{l}\text {-Participación en la producción agrícola (2007- } \\
\text { 2014) }\end{array}$ & $\begin{array}{l}\text { animales y mejora en la productividad alcanzada en el uso } \\
\text { de la tierra para actividades pecuarias. Y servicio hizo }\end{array}$ \\
\hline $\begin{array}{l}\text {-Variación de la producción agrícola (2007- } \\
\text { 2014) }\end{array}$ & $\begin{array}{l}\text { referencia al número de establecimientos y flujo de } \\
\text { demanda existente. }\end{array}$ \\
\hline Rendimiento & \\
\hline - Crecimiento del rendimiento agrícola & \\
\hline
\end{tabular}

Fuente: Elaboración propia con base en metodología de priorización preliminar

PNUD 2016 
En el resultado de esta matriz preliminar se obtuvo que los productos más viables y que son tentativamente priorizados bajo este análisis son en primer lugar la palma de aceite, seguido de arroz, maíz, aguacate, mango, ganado bovino y piscicultura (ver tabla 3).

Con esta información preliminar fueron convocadas cincuenta (50) personas el día 7 de octubre de 2016, para que participaran del taller \# 1 "priorización de sectores económicos potenciales alternativos al sector hidrocarburos". Allí participaron representantes de la Cámara de Comercio, el Servicio Nacional de Aprendizaje (SENA), representantes de los sectores productivos, Aso juntas ${ }^{31}$ y personas de la comunidad en general.

En este foro se realizó un ejercicio participativo de priorización que se basa en la metodología de la matriz de $V_{e s t e r}^{32}$, con el interés de construir información de fuente primaria que permitiera conocer las dinámicas económicas actuales e identificar aquellos sectores con mayores posibilidades de desarrollo para el fomento de la empleabilidad y la generación de valor.

Este ejercicio consistió en responder de común acuerdo y en consenso a preguntas de viabilidad e impacto de cada actividad, que se valoraban a través de una escala definida así: Muy alto 100; Alto 75; Medio 50; Bajo 25 y Nulo 0. Asignando así un puntaje a cada pregunta.

\footnotetext{
${ }^{31}$ Representantes de las juntas de acción comunal urbanas y rurales del municipio

${ }^{32}$ Herramienta creado por el químico y economista alemán Frederic Vester, que permite medir la relación causa - efecto y organiza los problemas en línea, identifica cuales problemas son el resultado de una serie de procesos o procedimientos incorrectos (Efectos) y cuáles son dinámicos porque su estructura e importancia los posiciona como el lugar clave que genera efectos a otras áreas y por eso se identifican como problemas causales, de mayor importancia.
} 
Tabla 2 Criterios de priorización de actividades/sectores productivos

\begin{tabular}{|c|c|}
\hline & d \\
\hline $\begin{array}{l}\text { ¿La actividad es generadora de empleo? } \\
\text { - ¿La actividad es generadora de valor } \\
\text { (riqueza)? } \\
\text { - ¿La actividad económica se encuentra } \\
\text { vinculada a algún eslabonamiento de alguna } \\
\text { cadena productiva definida como prioritaria para } \\
\text { el país? ¿La mayor parte de valor que genera la } \\
\text { - ¿La actividad puede resultar atractiva } \\
\text { actividad se retiene para el municipio o para la } \\
\text { región? } \\
\text { años? } \\
\text { adecuadamente la actividad podría generar } \\
\text { - } \quad \text { la los beneficiarios del desarrollo } \\
\text { vulnerable? } \\
\text { - }\end{array}$ & 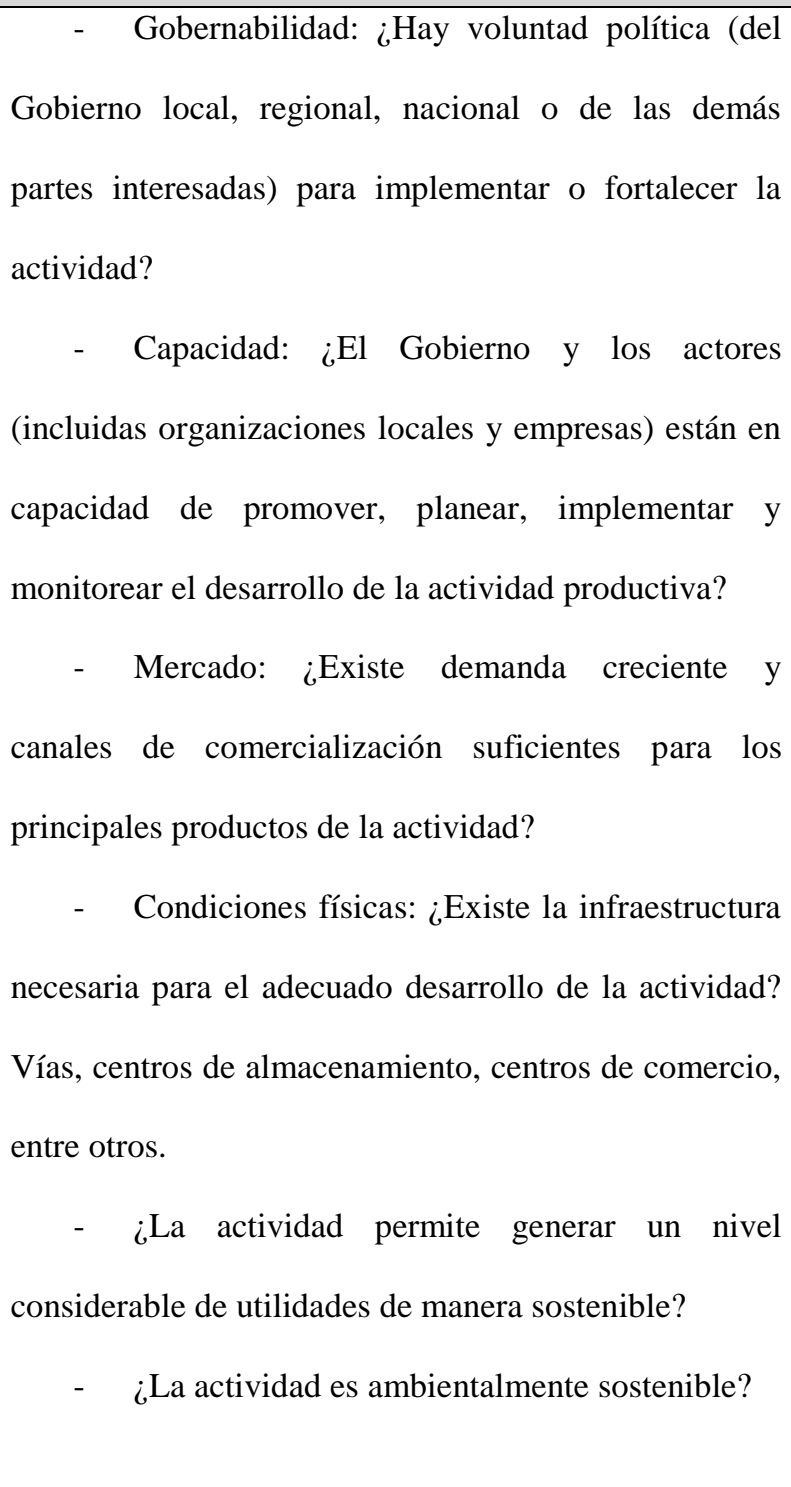 \\
\hline
\end{tabular}

Fuente: Guía metodológica del equipo de trabajo, Desarrollo y Mercado Laboral, PNUD (2015).

La suma de resultados para cada actividad, según los criterios de calificación, arrojó la evaluación de impacto y viabilidad de los sectores priorizados (Ver tabla 3). 
Tabla 3 Evaluación de impacto y viabilidad de los sectores priorizados

\begin{tabular}{|l|l|l|l|l|}
\hline \multicolumn{2}{|l|}{ INTERVENCIONES } & IMPACTO & VIABILIDAD & RANK* \\
\hline 1 & Maíz & 425 & 325 & $\mathbf{7 5 0}$ \\
\hline 2 & Palma & 650 & 400 & $\mathbf{1 0 5 0}$ \\
\hline 3 & Arroz & 500 & 350 & $\mathbf{8 5 0}$ \\
\hline 4 & Cacao & 550 & 425 & $\mathbf{9 7 5}$ \\
\hline 5 & Plátano & 475 & 400 & $\mathbf{8 7 5}$ \\
\hline 6 & Mango, aguacate, cítricos, & 575 & 425 & $\mathbf{1 0 0 0}$ \\
\hline 7 & Yuatilla, papaya, melón & & & \\
\hline 8 & Fríjol & 400 & 250 & $\mathbf{6 5 0}$ \\
\hline 9 & Piscicultura & 400 & 275 & $\mathbf{6 7 5}$ \\
\hline 10 & Ganadería (doble propósito) & 575 & 400 & $\mathbf{1 1 0 0}$ \\
\hline 11 & Ovino-caprinos & 475 & 350 & $\mathbf{9 7 5}$ \\
\hline 12 & Porcicultura & 500 & 325 & $\mathbf{8 2 5}$ \\
\hline 13 & Avicultura & 450 & 275 & $\mathbf{7 2 5}$ \\
\hline 14 & Turismo & 650 & 350 & $\mathbf{1 0 0 0}$ \\
\hline 15 & Ahuyama & 300 & $\mathbf{7 7 5}$ \\
\hline
\end{tabular}

Fuente: PNUD taller\#1de priorización, a partir de consulta a actores territoriales (2016).

*Se sombrean los productos con mayor puntaje

En esta fase de priorización se propusieron quince (15) sectores y productos de los cuales de acuerdo con la suma de las respuestas en consenso que sugiere la metodología Vester, se obtuvo que priorizados serían los siguientes: la palma de aceite, la cadena hortofrutícola (mango, aguacate, cítricos, patilla, papaya, melón), la piscicultura y el turismo; sin embargo, en talleres participativos que se realizaron posteriomente, la 
comunidad solicitó incluir la ganadería, el cacao, el maíz y el arroz ya que se trataba de sectores que estaban generando fuentes de empleo en el territorio (Ver tabla 4).

Tabla 4 Sectores priorizados

\begin{tabular}{|l|l|}
\hline Actividad productiva & Productos con potencial identificados \\
\hline Piscicultura & Producción y transformación de Bocachico, cachama y mojarra \\
\hline Cadena hortofrutícola & Producción y transformación de Mango, aguacate, cítricos, patilla, papaya, melón \\
\hline Ganadería & Ganadería bovina (leche y carne). \\
\hline Turismo & Ecoturismo \\
\hline Palma de aceite & Producción y transformación \\
\hline Cacao & Producción \\
\hline Maíz & Producción \\
\hline Arroz & Producción \\
\hline
\end{tabular}

Fuente: PNUD talleres Vester, a partir de consulta a actores territoriales (2016).

En un cuarto momento se realizó un encuentro con setecientos noventa (790) estudiantes de grado $10^{\circ}$ y $11^{\circ}$ en cinco (5) instituciones educativas, en los corregimientos de Minas, La curva, Terraplén y en la cabecera municipal, vinculando a las instituciones educativas Sor Matilde Sastoque y San Martín de Tours. Con los estudiantes se desarrolló un instrumento de caracterización socioeconómica y ocupacional tenía como objetivo tener conocimiento de las características socioeconómicas de los estudiantes e identificar su visión de futuro en términos de formación, es decir, para conocer en qué tipo de actividad o programa académico estaban interesados y en dónde consideraban que podían realizarlo y si después de ello tenían o no interés de volver al municipio

Así al finalizar los estudios de bachillerato, el $40 \%$ de los estudiantes se visualiza viviendo en otro municipio, específicamente por razones de trabajo, mientras que el 38\% de 
los estudiantes aspira estudiar fuera del municipio. Por otro lado, el 16\% de los estudiantes espera quedarse en el municipio por motivos de trabajo y el $4 \%$ por cuestiones de estudio. En relación con los lugares preferidos para adelantar estudios técnicos, tecnológicos y universitarios, los estudiantes escogieron principalmente: Bucaramanga (38\%), Ocaña (16\%), Bogotá (10\%), Pamplona (4\%), Medellín (4\%), Barranquilla (3\%), mientras que los destinos internacionales de mayor interés se encuentra Estados Unidos y Argentina (2\%).

En relación con el máximo nivel educativo que aspiran alcanzar los estudiantes: el 46\% aspira a tener formación universitaria, específicamente aquellos con intención de viajar y quedarse en Valledupar mientras que un $39 \%$ presenta interés por realizar un posgrado en especial aquellos con intenciones de estudiar en la capital del país, fuera del país u otras ciudades colombianas. De otra parte, el 10\% de los estudiantes desea obtener formación técnica o tecnológica, finalmente. un 3\% aspira quedarse con sus estudios de bachillerato y vivir en el municipio.

Con respecto a las carreras preferidas dentro de las áreas del conocimiento de mayor interés para los estudiantes del municipio., se destacan las relacionadas con ingenierías (30\%) como, ingeniería civil, ingeniería ambiental, ingeniería industrial, ingeniería de petróleo, ingeniería electrónica, ingeniería naval, ingeniería de sistemas e ingeniería mecánica, seguido por carreras del área de ciencias de la salud (30\%) como psicología, fisioterapia, odontología, enfermería o medicina y en tercer lugar administración de empresas $(6 \%)$ o veterinaria $(6 \%)$.

Por otra parte, el quinto momento del proceso estudiado estuvo destinado al taller \#2 para la "caracterización de las cadenas de valor de los sectores priorizados". En este 
taller se organizaron mesas de trabajo por sectores priorizados, estas mesas fueron apoyadas por dos estudiantes de último semestre de carreras universitarias que se encontraban en el municipio apoyando el Programa Nacional Manos a la Paz ${ }^{33}$ que coordina el PNUD desde el área de gobernabilidad, ellos fueron apoyo logístico y de coordinación para las mesas de trabajo junto con la persona que desde el territorio operaba como enlace para la gestión de las convocatorias mediante diálogo directo con la alcaldía municipal y demás actores del territorio.

De acuerdo con la información suministrada por los productores locales en el taller realizado el día 25 de noviembre de 2016, al cual asistieron 40 personas entre empresarios y productores, se obtuvo que el estado de las cadenas de valor de los diferentes productos y sectores coincidían en las problemáticas identificadas en los cuatro (4) eslabones: insumos, producción transformación y comercialización. Con este marco preliminar y los demás identificados en el análisis de información secundaria se orientó el próximo ejercicio para identificar con detalle el conjunto de situaciones indeseadas

Con lo refertes mencionados en un sexto momento se llevó a cabo el taller 3 para la “identificación de problemáticas causas y efectos alrededor de la empleabilidad y el emprendimiento". El análisis del empleo se enfocó en el trabajo decente y sus pilares. Este taller tuvo tres (3) réplicas con la misma dinámica en enero 30, 31 y febrero 1 de 2017, en dos corregimientos y uno en la zona urbana. A continuación, se sintetizan las problemáticas, causas y efectos considerados por la comunidad en los talleres:

\footnotetext{
${ }^{33}$ Es una iniciativa de la Alta Consejería para el Posconflicto que cuenta con el apoyo del Programa de Naciones Unidas para el Desarrollo en Colombia -PNUD-, orientado a fortalecer las capacidades de construcción de paz en los territorios, vinculando a ciudadanos y ciudadanas comprometidos con el desarrollo del país. https://www.manosalapaz.com/
} 
Figura 7 problemáticas causas y efectos alrededor del desempleo

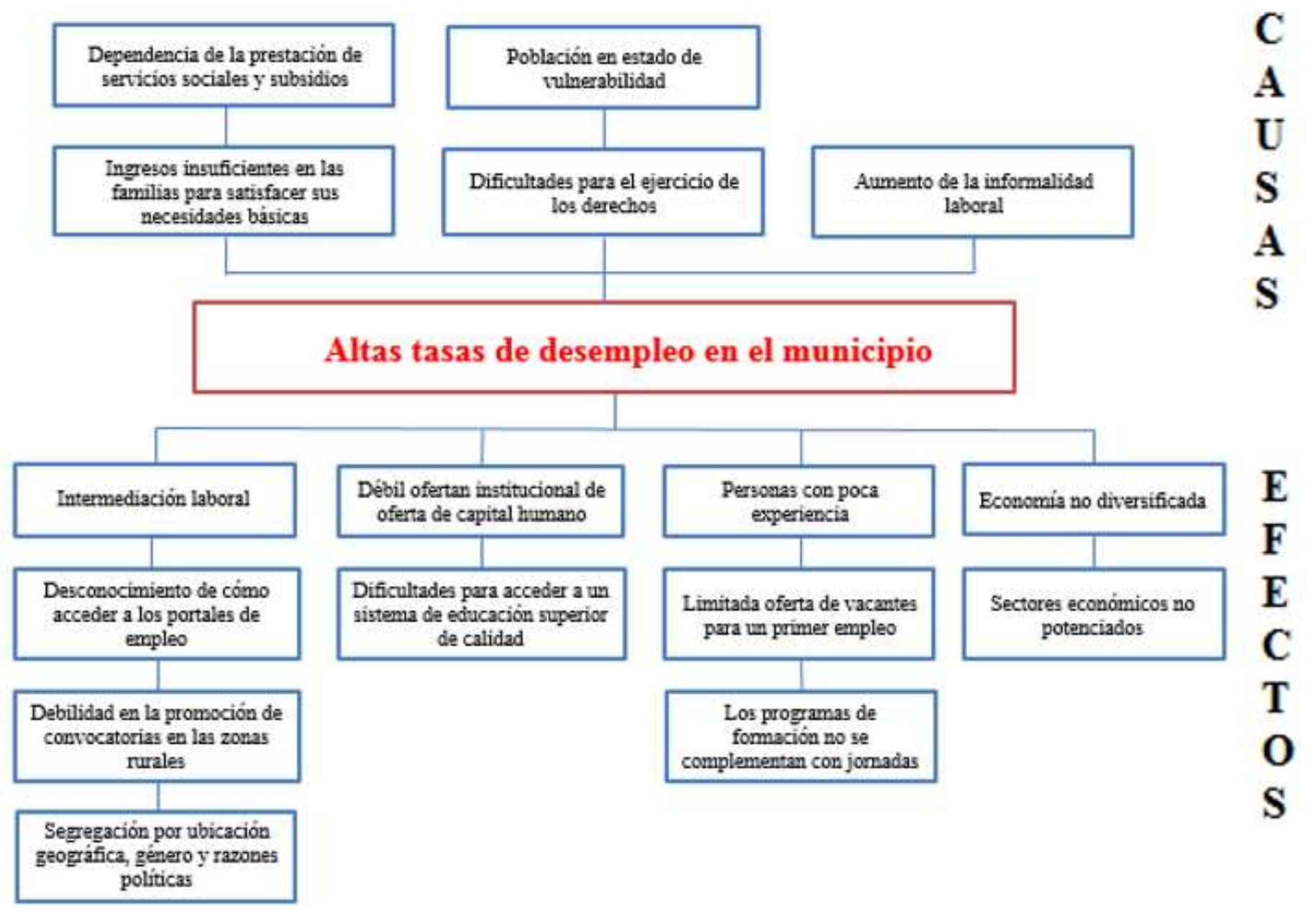

Fuente: PNUD Documento Bases para la formulación de la política pública de empleo y emprendimiento en San Martín Cesar 2017 
Figura 8 problemáticas causas y efectos alrededor del emprendimiento

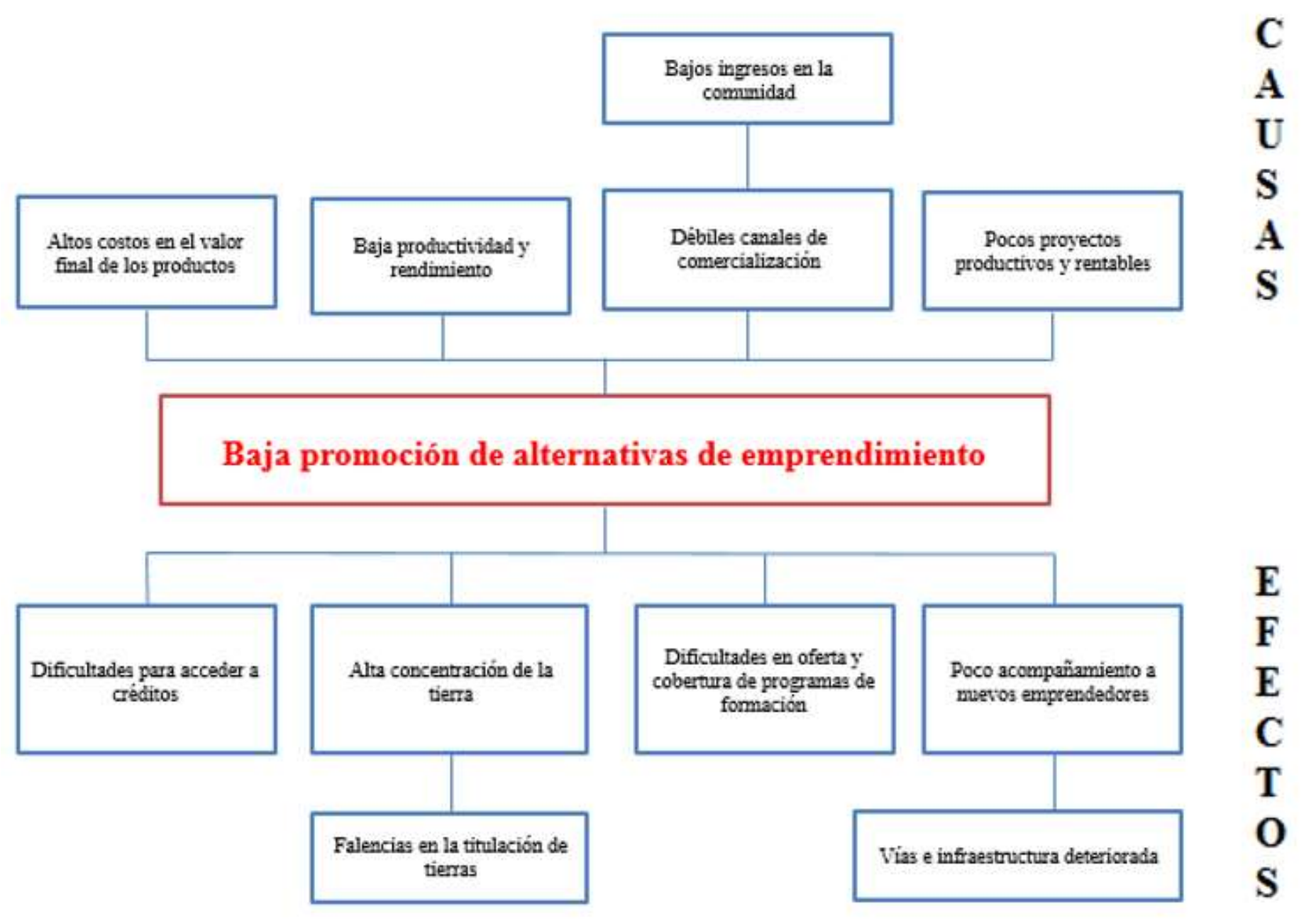

Fuente: PNUD Documento Bases para la formulación de la política pública de empleo y emprendimiento en San Martín Cesar 2017 
Figura 9 problemáticas causas y efectos alrededor del trabajo decente

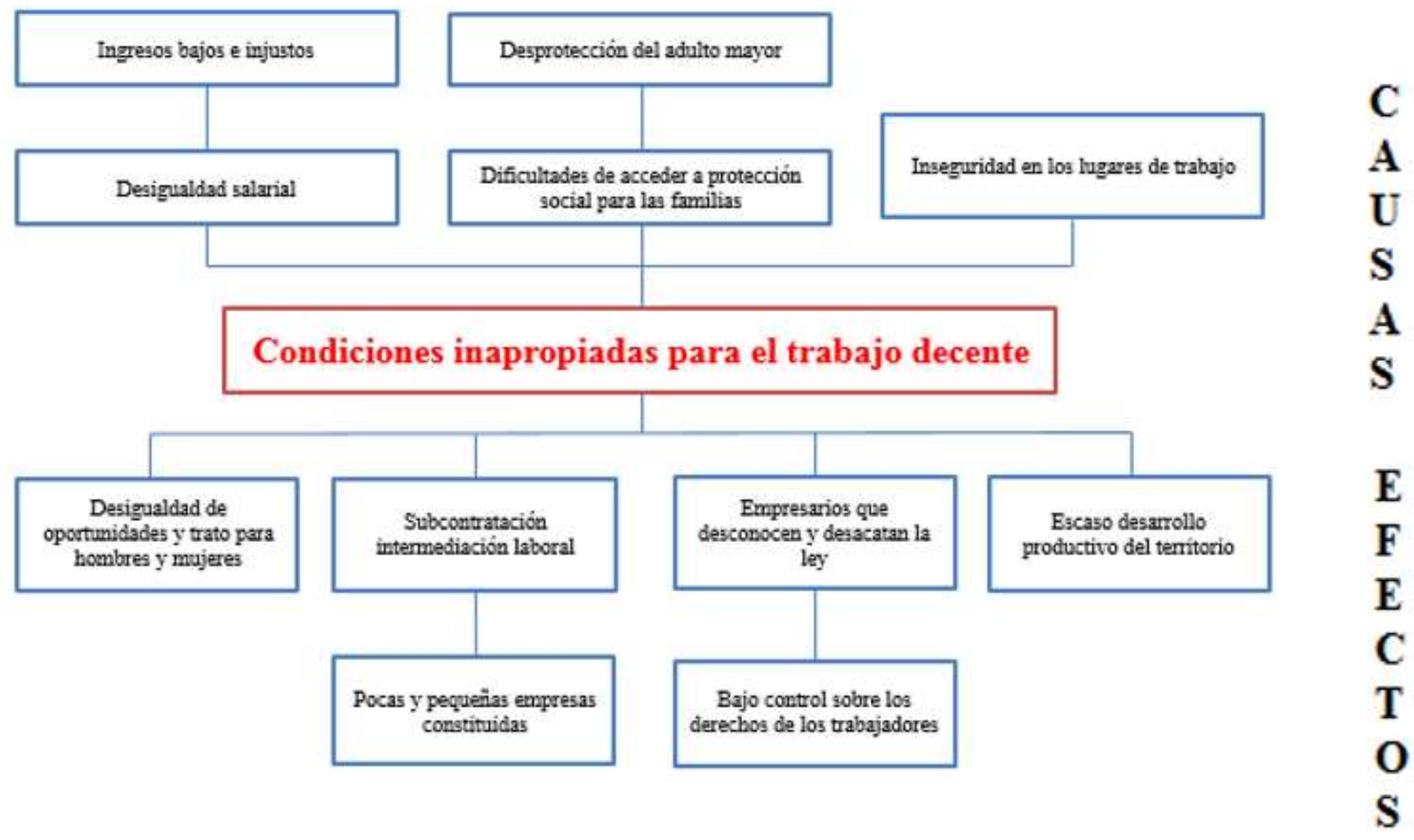

Fuente: PNUD Documento Bases para la formulación de la política pública de empleo y emprendimiento en San Martín Cesar 2017 
En un séptimo momento, el 24 de febrero de 2017, fue desarrollado el taller \#4 ${ }^{34}$ para la "definición de líneas estratégicas de la política pública de empleo y emprendimiento". Este taller fue realizado con la participación de líderes comunitarios de la zona rural y urbana contó con da una metodología propositiva para construir respuestas frente a las problemáticas identificadas en diferentes lugares. Así, los participantes propusieron tres (3) líneas estratégicas que permitirían mediante acciones concretas, generar un entorno viable para el desarrollo productivo y el trabajo decente en el territorio, las cuales son: (a) capacidades locales para promover, planear y gestionar oportunidades para el desarrollo productivo sostenible y el trabajo decente; (b) recursos, servicios, infraestructura, innovación y tecnología y, (c) población con conocimientos, habilidades y destrezas. Estas líneas se especificarán en el apartado 3.4 de este documento.

En un octavo momento, lo identificado en los talleres y en el trabajo de campo, así como la caracterización del territorio, las problemáticas y las líneas estratégica del plan de acción fue socializada con seis (6) de los once (11) concejales del cabildo municipal el día 3 de marzo de 2017. Aunque muchos de los concejales presentes este día habían participado en los talleres era importante hacer una primera socialización de los resultados consolidados en el marco del cabildo. Con el propósito de articular los aportes de los concejales, fue organizada una cena de trabajo, en el cabildo, así que en este proceso fue importante la gestión y el apoyo del Presidente del Concejo Municipal y el cabildeo del equipo de trabajo para favorecer la apertura y el diálogo político en torno a lo logrado por el proceso participativo.

\footnotetext{
${ }^{34}$ En el marco del taller \#4, la emisora municipal San Martin De Tours Stereo, solicito al equipo PNUD y de la ETH generar opinión y comentarios sobre lo que se ha venido desarrollando en el proceso lo que permitió su visibilización al aire, a través de la misma se realizaron las convocatorias de talleres
} 
Finalmente, en un noveno momento, fue desarrollado el taller \#5 para la “socialización de líneas estratégicas de la política pública de empleo y emprendimiento". En este espacio fueron socializadas con la comunidad los alcances y acciones que componen cada línea de la política pública. El ejercicio incluyó el desarrollo de tres mesas de trabajo, cada una de ellas representó una línea estratégica y tenía como reto representar a los demás participantes del taller, de la manera más creativa posible las acciones contempladas por cada línea asumida. Dicho ejercicio también contó con un juego de roles en el que cada acción era representada por diferentes personas de la comunidad, en la que cada rol representaba una institución o entidad, permitiendo que evidenciaran incluso lo difícil que es construir acuerdos para cosas pequeñas y entender que la sinergia entre actores aunque compleja, es posible y requiere interés, seguimiento, monitoreo y control.

\subsection{Resultados del proceso de formulación participativa.}

Como resultado de los talleres participativos y de los ejercicios de caracterización, fue posible identificar con detalle las problemáticas que el municipio presenta en relación al empleo y el emprendimiento; así como también fueron construidas las "acciones" o “soluciones identificadas" para cada una de las tres (3) líneas estratégicas priorizadas, acciones consignadas en las tablas 5,6 y 7.

Estas líneas hacen parte del plan de acción concertado con la comunidad y se encuentran expresadas en el documento "Bases para la formulación de la política pública de empleo y emprendimiento en San Martín Cesar" el cual hace parte integral y se constituye 
en el documento técnico que soporta el documento proyecto de acuerdo Política Pública de empleo y emprendimiento San Martin Cesar, el cual está en poder de la alcaldía municipal para su consideración y evaluación el cual se espera sea presentado ante el Concejo Municipal con el objetivo de convertirlo en acuerdo municipal.

Tabla 5 Acciones y problemáticas a atender por la línea \#1 capacidades locales para promover, planear y gestionar oportunidades para el desarrollo productivo sostenible y el trabajo decente

\begin{tabular}{|c|c|}
\hline \multicolumn{2}{|c|}{ ACTORES CON POSIBLES FUENTES DE FINANCIACIÓN } \\
\hline \multicolumn{2}{|c|}{$\begin{array}{l}\text { Gobernación del Cesar 2. Alcaldía Municipal 3. Empresas Privadas 4. Cooperación Internacional 5. SENA } 6 . \\
\text { Instituciones Educativas 6. Ministerio de Agricultura. 7. Ministerio de trabajo 8. FONTUR. 9. Departamento } \\
\text { Nacional de Planeación 10. Juntas de acción comunal 11. Servicio Público de Empleo 12. Comisaria de } \\
\text { familia 12. ICBF 13. Comunidad 14. Asistencia Técnica Agropecuaria. 15. Ministerio Turismo 16. Ministerio } \\
\text { de Comercio }\end{array}$} \\
\hline SITUACIÓN A CAMBIAR & SOLUCIONES IDENTIFICADAS \\
\hline Inadecuada intermediación laboral & $\begin{array}{l}\text { Campañas de capacitación sobre el manejo adecuado de } \\
\text { plataformas de gestión laboral }\end{array}$ \\
\hline $\begin{array}{l}\text { Desarticulación con los instrumentos de } \\
\text { planeación nacional, departamental } \\
\text { regional y municipal. }\end{array}$ & $\begin{array}{l}\text { Fortalecimiento del capital humano en las entidades públicas del } \\
\text { territorio y de los instrumentos de planeación para la articulación } \\
\text { interinstitucional }\end{array}$ \\
\hline \multirow[t]{2}{*}{$\begin{array}{l}\text { Empresarios que desconocen y no } \\
\text { emplean la ley. }\end{array}$} & $\begin{array}{l}\text { Campañas de sensibilización, seguimiento y control sobre el } \\
\text { cumplimiento de los principios y derechos fundamentales en el } \\
\text { trabajo y el trabajo decente } \\
\text { Gestión de escenarios para el primer empleo }\end{array}$ \\
\hline & as de promoción y \\
\hline
\end{tabular}




\begin{tabular}{|ll|l|l|}
\hline & & protección y seguridad social de los trabajadores y trabajadoras \\
\hline Condiciones económicas, sociales y & Campañas de sensibilización a padres de familia sobre los \\
culturales que propenden al trabajo & derechos y la importancia de la educación desde la primera \\
infantil. & & infancia. \\
\hline Condiciones para la asociatividad & Socialización de oferta institucional para productores de los \\
deterioradas & & sectores priorizados
\end{tabular}

Fuente: Elaboración propia con base en documento Bases para la formulación de la política pública de empleo y emprendimiento en San Martín Cesar

Tabla 6 Acciones y problemáticas a atender por la línea \#2 recursos, servicios, infraestructura, innovación y tecnología.

\begin{tabular}{|c|c|}
\hline \multicolumn{2}{|c|}{ ACTORES CON POSIBLES FUENTES DE FINANCIACIÓN } \\
\hline \multicolumn{2}{|c|}{$\begin{array}{l}\text { 1. Gobernación del Cesar 2. Alcaldía Municipal 3. Empresas Privadas 4. Cooperación Internacional 5. SENA } \\
\text { 6. Instituciones Educativas 6. Ministerio de Agricultura. 7. FONTUR 8.Fundaciones, ONGs }\end{array}$} \\
\hline SITUACIÓN A CAMBIAR & SOLUCIONES IDENTIFICADAS \\
\hline \multirow{6}{*}{ Déficit de capital humano formado. } & Promover campañas de motivación hacia los procesos formativos \\
\hline & Fortalecer la oferta de programas de formación \\
\hline & $\begin{array}{l}\text { Orientar los programas de formación para el trabajo hacia los } \\
\text { requerimientos de mercado }\end{array}$ \\
\hline & $\begin{array}{l}\text { Aumentar la cobertura y los medios de divulgación de las } \\
\text { convocatorias académicas }\end{array}$ \\
\hline & Formación en competencias blandas \\
\hline & Gestión de escenarios para las prácticas laborales \\
\hline
\end{tabular}

Fuente: Elaboración propia con base en documento Bases para la formulación de la política pública de empleo y emprendimiento en San Martín Cesar 
Tabla 7 Acciones y problemáticas a atender por la línea \#3 población con conocimientos, habilidades y destrezas

\begin{tabular}{|c|c|}
\hline \multicolumn{2}{|c|}{ ACTORES CON POSIBLES FUENTES DE FINANCIACIÓN } \\
\hline \multicolumn{2}{|c|}{$\begin{array}{l}\text { 1. Gobernación del Cesar 2. Alcaldía Municipal 3. Empresas Privadas 4. Cooperación Internacional 5. Fonade } \\
\text { 6. Instituciones Educativas 6. Ministerio de Agricultura. 7. FONTUR 8. Unidad de Restitución de Tierras } 9 . \\
\text { Asociaciones de productores. 10. Juntas de Acción Comunal. 11. Entidades Bancarias y de financiación. } 12 . \\
\text { Ministerio Turismo 13. Ministerio de Comercio }\end{array}$} \\
\hline $\begin{array}{l}\text { SITUACIÓN } \\
\text { CAMBIAR }\end{array}$ & SOLUCIONES IDENTIFICADAS \\
\hline \multirow[b]{2}{*}{$\begin{array}{l}\text { Dificultades para } \\
\text { acceder al sistema } \\
\text { financiero. }\end{array}$} & Jornada de titulación de tierras. \\
\hline & $\begin{array}{l}\text { Jornada de acercamiento del sistema bancario y el Fondo de Garantías a los } \\
\text { productores. } \\
\text { Diseñar/implementar la: "Ruta de Acompañamiento a Productores para acceso a } \\
\text { activos: sistema financiero, maquinaria y/o insumos." }\end{array}$ \\
\hline $\begin{array}{l}\text { Asistencia técnica } \\
\text { agropecuaria } \\
\text { insuficiente y poco } \\
\text { pertinente. }\end{array}$ & Definir la Estrategia de Asistencia Técnica General y Especializada para el municipio. \\
\hline $\begin{array}{l}\text { La planeación } \mathrm{y} \\
\text { gestión de la }\end{array}$ & $\begin{array}{l}\text { Priorizar el mantenimiento de vías terciarias a partir del mapa de producción } \\
\text { agropecuaria y la oferta turística en el Municipio. }\end{array}$ \\
\hline $\begin{array}{l}\text { infraestructura vial } \\
\text { no está en función de } \\
\text { los sectores } \\
\text { productivos. }\end{array}$ & $\begin{array}{l}\text { Gestionar recursos para el mejoramiento vial, a partir del mapa de producción } \\
\text { agropecuaria y la oferta turística en el municipio. }\end{array}$ \\
\hline $\begin{array}{l}\text { Procesos productivos } \\
\text { que no apropian la }\end{array}$ & $\begin{array}{l}\text { Elaborar la Visión Estratégica del Sector Agropecuario y Turístico con referentes } \\
\text { internacionales, bajo un enfoque de cadena de valor y que permita el acceso a }\end{array}$ \\
\hline
\end{tabular}




\begin{tabular}{|l|l|l|}
\hline tecnología y la & mercados especializados que generen valor agregado. \\
innovación en sus & Definir las posibilidades de acceso y uso de la tecnología requerida por cada sector \\
cadenas de valor. & (agropecuario, turístico), de tal manera que se aumente su productividad y \\
& competitividad.
\end{tabular}

Fuente: Elaboración propia con base en documento Bases para la formulación de la política pública de empleo y emprendimiento en San Martín Cesar

Los primeros ejercicios participativos permitieron evidenciar que en el imaginario de una gran parte de la comunidad en función del significado de la política pública de empleo para el municipio adoptada para el 2016 y años anteriores. Esta respondía únicamente a la gestión del empleo dentro del sector hidrocarburos, situación que fue empezando a cambiar con los avances del proceso, se empezó a compartir una visión de potenciamiento económico y de generación de nuevos emprendimientos que generen empleos decentes.

Se evidencia en estos árboles de problemas y en los resultados de acciones concretas propuestas y solicitadas por la comunidad, una débil presencia institucional en función de la generación y protección del empleo, que no ofrece condiciones para garantizar ingresos y trabajo decente. A su vez, los participantes de las zonas rurales sienten un desamparo no solo en dirección de proyectos y recursos de inversión pública dirigidos a proyectos productivos, sino de gestión con otras entidades, por ejemplo, de carácter educativo, para promover desarrollo humano y así aumentar las posibilidades de acceder a un empleo decente o potenciar un emprendimiento.

La parte estratégica y las acciones concretas que se han definido con la comunidad, tiene muchas similitudes con las acciones que se establecen en el plan de desarrollo actual 
del municipio y el departamento, lo que indica que es muy viable poder concretar las acciones propuestas si los futuros mandatarios atienden a la visión estratégica de la política pública de empleo y emprendimiento para San Martín Cesar.

Las barreras que enfrenta el campesino para garantizar sus ingresos son suficientes para desinteresarse por producir y para desmotivarse frente a las propuestas del Estado que pretenden promover el desarrollo del sector agropecuario; son muchas las barreras que encuentra para producir y lograr un precio de venta que garantice el retorno de su inversión y algo de utilidad, bien sea por condiciones estructurales de carácter nacional pero también por desinterés de los actores territoriales y desarticulación entre la escala local y la nacional.

Junto al abandono estatal, explicado en parte por la limitación de recursos y de capacidad institucional, es importante anotar que la asociatividad y el trabajo en grupos organizados por productores también es reducido, y poco han realizado las instituciones por fortalecerlo.

Como factor importante y que permitiría garantizar la incidencia de esta política pública en otros instrumentos de planeación y en resultados reales y tangibles, la comunidad manifestó su interés por participar de un comité de seguimiento y evaluación de los planes de acción de la política pública. 


\section{Conclusiones y recomendaciones}

Luego de analizar en el apartado 2, cómo un problema de interés colectivo se inserta en la agenda política y qué elementos puede contener una política pública de tipo participativa, a continuación se presenta el análisis evaluativo del proceso desarrollado en el municipio de San Martín, en relación con la formulación de la política pública de empleo y emprendimiento, acogiendo elementos conceptuales que brindan los enfoques, modelos y aproximaciones previamente abordados, a partir de algunos de los autores explorados. En primer lugar, se analizan elementos del proceso de construcción del problema y el agendamiento político del mismo (Ver tabla 8) y en segundo lugar, se analiza el carácter participativo de la Política Pública formulada (Ver tabla 9).

Tabla 8 Aproximaciones conceptuales sobre Problema público y agendamiento político: el Caso Política Pública de empleo y emprendimiento San Martín Cesar

\begin{tabular}{|c|c|c|}
\hline AUTOR & VARIABLES & CASO SAN MARTÍN \\
\hline $\begin{array}{l}\text { Lenoir } \\
\text { (1986) }\end{array}$ & $\begin{array}{l}\text { la posición social } \\
\text { ocupada por los } \\
\text { grupos promotores }\end{array}$ & $\begin{array}{l}\text { Entidades de carácter nacional promovieron el proceso, contando con el } \\
\text { apoyo político de la normatividad, instrumentos de planeación y el interés } \\
\text { de la alcaldía municipal. } \\
\text { Existieron recursos económicos para los ejercicios que facilitarían una } \\
\text { adecuada formulación. } \\
\text { Se contó con el interés de las comunidades expresado incluso en las } \\
\text { protestas que se presentaron para que otros sectores económicos se } \\
\text { vincularan al proceso de formulación y para que potencien en el } \\
\text { territorio. }\end{array}$ \\
\hline Casar & Disposición & Existió disposición desde las entidades nacionales y la alcaldía \\
\hline
\end{tabular}




\begin{tabular}{|c|c|c|}
\hline AUTOR & VARIABLES & CASO SAN MARTÍN \\
\hline $\begin{array}{l}\text { Maldonado } \\
\text { (2010) }\end{array}$ & institucional & $\begin{array}{l}\text { municipal, representado en recursos, espacios, tiempos y aportes para } \\
\text { visibilizar el problema e identificar soluciones participativas. } \\
\text { Sin embargo, en la actualidad por un proceso de revocaría la propuesta de } \\
\text { acuerdo no s ha presentado ante el Concejo Municipal. }\end{array}$ \\
\hline & $\begin{array}{l}\text { Competencias de la } \\
\text { autoridad pública }\end{array}$ & $\begin{array}{l}\text { El proceso y los resultados se articularon con la normatividad nacional y } \\
\text { aterrizado a la realidad territorial, lo que exige las competencias de las } \\
\text { entidades nacionales y municipales que hicieron posible que el proceso } \\
\text { iniciara, se desarrollara y llegara a incidir en la agenda política. }\end{array}$ \\
\hline $\begin{array}{l}\text { Cobb } \\
\text { Elder }\end{array}$ & $\begin{array}{l}\text { Lo que es y lo que } \\
\text { debería ser }\end{array}$ & $\begin{array}{l}\text { Para identificar y validar la necesidad de la política pública se revisaron } \\
\text { muchas aproximaciones y políticas similares aprobadas. Se discutió el } \\
\text { diagnóstico del territorio y se generó un proceso de diálogo deliberativo } \\
\text { en torno a las visiones de desarrollo de los diferentes actores territoriales. }\end{array}$ \\
\hline$(1972)$ & $\begin{array}{l}\text { La claridad con que } \\
\text { se exprese el } \\
\text { problema }\end{array}$ & $\begin{array}{l}\text { Antes de iniciar el proceso de formulación, se conocía parte del problema } \\
\text { y parte de sus causas, en el marco de la formulación participativa, se } \\
\text { identificaron los detalles, las causas, los efectos, las coincidencias y } \\
\text { diferencias entre la zona urbana y rural. Todo ello permitió compartir una } \\
\text { visión territorial del problema, así como construir información } \\
\text { socialmente compartida para identificar particularidades del problema } \\
\text { para diferentes contextos y actores. }\end{array}$ \\
\hline \multirow{3}{*}{$\begin{array}{l}\text { Chevallier } \\
\text { (1986) }\end{array}$} & $\begin{array}{l}\text { Participación de los } \\
\text { partidos político y } \\
\text { los gremios }\end{array}$ & $\begin{array}{l}\text { En el proceso participaron asociaciones y agremiaciones de productores } \\
\text { con potencial económico. } \\
\text { Los partidos políticos participaron mediante sus concejales electos. }\end{array}$ \\
\hline & $\begin{array}{l}\text { Participación de los } \\
\text { mediadores } \\
\text { sociales }\end{array}$ & - $\quad$ Programa de las Naciones Unidas Para el Desarrollo PNUD \\
\hline & $\begin{array}{l}\text { Participación de los } \\
\text { funcionaros }\end{array}$ & $\begin{array}{l}\text { Desde la Alcaldía municipal se vincularon los siguientes actores: } \\
\text { - } \quad \text { Alcalde Municipal }\end{array}$ \\
\hline
\end{tabular}




\begin{tabular}{|c|c|c|}
\hline AUT & VARIABLES & CASO SAN MARTÍN \\
\hline & públicos & $\begin{array}{ll}\text { - } & \text { Secretario de gestión social } \\
\text { - } & \text { Funcionarios equipo de asistencia técnica agropecuaria ATA } \\
\text { - } & \text { Funcionarios ETH }\end{array}$ \\
\hline \multirow{3}{*}{$\begin{array}{l}\text { Garraud } \\
\text { (1999) }\end{array}$} & $\begin{array}{l}\text { De la } \\
\text { movilización }^{35}\end{array}$ & $\begin{array}{l}\text { Protestas y marchas en contra del Fracking, visibilizadas en medios. } \\
\text { Apoyado por grupos sociales y comunidades. (los artículos de prensa no } \\
\text { registran interés ni apoyo de grupos políticos específicos contradictores) } \\
\text { En el marco del taller \#4, la emisora municipal San Martin De Tours } \\
\text { Stereo, solicito al equipo PNUD y de la ETH generar opinión y } \\
\text { comentarios sobre lo que se ha venido desarrollando en el proceso lo que } \\
\text { permitió su visibilización al aire, a través de la misma se realizaron las } \\
\text { convocatorias de talleres }\end{array}$ \\
\hline & La anticipación & $\begin{array}{l}\text { La formulación de la política pública evidencia el interés por construir } \\
\text { respuestas que ofrezcan alternativas a las causas de las protestas, así como } \\
\text { posibilidades para reducir el inconformismo e impedir que el tamaño del } \\
\text { problema crezca, si no se avanza en la construcción de alternativas desde } \\
\text { las políticas públicas. } \\
\text { Sin embargo, el hecho de que la comunidad halla protestado y buscado } \\
\text { espacios para visibilizar el problema, fue lo que garantizo este resultado } \\
\text { de conducir este instrumento de planeación, esta situación se presenta en } \\
\text { otros territorios pero si el problema no se visibiliza la institucionalidad } \\
\text { difícilmente atiende a dichas problemáticas. }\end{array}$ \\
\hline & $\begin{array}{l}\text { La acción } \\
\text { corporativista }\end{array}$ & $\begin{array}{l}\text { Esta situación no se presentó, ya que fue desde la ETH, que se propuso } \\
\text { anticiparse a temas que generen inconformidad en relación al desempleo y }\end{array}$ \\
\hline
\end{tabular}

${ }^{35}$ El de la movilización, que tiene elementos de movilización social y mediatización que amplía la audiencia y la atención al problema postulado y proviene desde la base.

${ }^{36} \mathrm{El}$ de la oferta pública, que proviene de organizaciones políticas con propuestas que buscan ganar apoyo y debilitar al gobierno, propósito para el cual emplean medios de comunicación y ampliación del debate político con espectadores sociales.

${ }^{37}$ El de la mediatización, que proviene desde medios de comunicación, no siempre cuenta con demandas sociales y su momento de visibilidad está altamente ligado a la búsqueda de rating 


\begin{tabular}{|l|l|l|}
\hline AUTOR & VARIABLES & CASO SAN MARTÍN \\
\hline & silenciosa $^{38}$ & los ingresos de los habitantes \\
\hline
\end{tabular}

Fuente: Elaboración propia 2017

Tabla 9 Aproximaciones conceptuales sobre Política Pública participativa: el Caso Política Pública de empleo y emprendimiento San Martín Cesar

\begin{tabular}{|c|c|c|}
\hline AUTOR & APROXIMACIÓN & DESCRIPCIÓN CASO SAN MARTÍN \\
\hline \multirow[b]{2}{*}{$\begin{array}{l}\text { Cunill } \\
\text { (1997) }\end{array}$} & 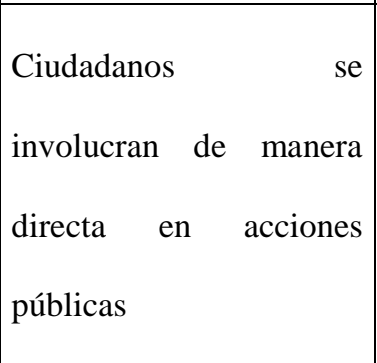 & $\begin{array}{l}\text { Desde los talleres de inicio y hasta el final del proceso se contó con } \\
\text { la presencia de líderes comunitarios, hubo líderes que asistieron y } \\
\text { aportaron en todos los talleres y se contó con personas de gran parte } \\
\text { del territorio y con rangos de edad desde los } 18 \text { hasta más de } 80 \\
\text { años. }\end{array}$ \\
\hline & $\begin{array}{l}\text { Esta participación pone } \\
\text { en contacto a los } \\
\text { ciudadanos y al Estado, } \\
\text { en la definición de las } \\
\text { metas colectivas y las } \\
\text { formas de alcanzarlas }\end{array}$ & $\begin{array}{l}\text { Las mesas fueron mediadas por funcionarios del Estado } \\
\text { específicamente de la ETH, con apoyo técnico del PNUD. } \\
\text { Desde la identificación de problemas, hasta la definición de acciones } \\
\text { y líneas estratégicas la comunidad fue pilar de los aportes. }\end{array}$ \\
\hline \multirow{3}{*}{$\begin{array}{l}\text { Ziccardi } \\
\text { (1998) }\end{array}$} & \multicolumn{2}{|l|}{ Tipo de participación } \\
\hline & Institucionalizada & $\begin{array}{l}\text { Se encuentra contenida en el marco legal y normativo, } \\
\text { De carácter global: ODS, recomendaciones OIT } \\
\text { Nacional: Constitución Política, decretos y leyes } \\
\text { Municipal: Decretos y acuerdos. }\end{array}$ \\
\hline & Autónoma & No Sucedió, al no ser organizada desde la comunidad de San Martín \\
\hline
\end{tabular}

${ }^{38}$ Que proviene de grupos organizados y de poder que pueden permear con su influencia las agendas políticas. 


\begin{tabular}{|c|c|c|}
\hline & & \\
\hline & $\begin{array}{l}\text { Promueve una cultura } \\
\text { democrática }\end{array}$ & $\begin{array}{l}\text { Los talleres se desarrollaron con convocatorias abiertas. Allí las } \\
\text { personas opinaban con vos y voto, sobre la decisiones y acciones } \\
\text { que consideraban más pertinentes para la formulación, en estos } \\
\text { talleres participaron en la misma mesa, personas de la comunidad, } \\
\text { líderes comunitarios, funcionarios públicos y concejales del } \\
\text { municipio }{ }^{39} \text {. }\end{array}$ \\
\hline & $\begin{array}{l}\text { Hace más eficaces la } \\
\text { decisión y la gestión } \\
\text { públicas }\end{array}$ & $\begin{array}{l}\text { Permitió identificar con claridad las problemáticas, sus causas y sus } \\
\text { efectos y dese allí la experticia de los habitantes del territorio y el } \\
\text { conocimiento del equipo técnico de apoyo encontraron opciones y } \\
\text { alternativas de solución aplicables y viables. }\end{array}$ \\
\hline & $\begin{array}{l}\text { Puede llegar a constituir } \\
\text { un mecanismo para el } \\
\text { empoderamiento social }\end{array}$ & $\begin{array}{l}\text { Desde los talleres la exigencia más común y constante de los } \\
\text { participantes fue hacer parte del equipo de seguimiento y que } \\
\text { existieran espacios amplios de socialización sobre los resultados y } \\
\text { avances }\end{array}$ \\
\hline & $\begin{array}{l}\text { Ciudadanos participan } \\
\text { en las etapas que } \\
\text { comprenden la } \\
\text { definición, } \\
\text { elaboración, } \\
\text { implementación y la } \\
\text { evaluación de la política. }\end{array}$ & $\begin{array}{l}\text { En este proceso se focalizó la participación en las fases } 1 \text { y } 2 \text {, como } \\
\text { se describió en los seis (6) talleres participativos del capítulo 3. Es } \\
\text { necesario generar un proceso d seguimiento, control social y } \\
\text { evaluación del mismo con participación, estudios subsiguientes } \\
\text { debería sistematizar su desarrollo. }\end{array}$ \\
\hline $\begin{array}{l}\text { Manuel } \\
\text { Canto Chac, }\end{array}$ & $\begin{array}{l}\text { Se le concede a la } \\
\text { ciudadanía la capacidad } \\
\text { de expresar razones y de }\end{array}$ & $\begin{array}{l}\text { Las metodologías de cada mesa de trabajo en los seis (6) talleres, } \\
\text { daban voz y voto a las decisiones que allí se concertaran. } \\
\text { Cada eiercicio tuvo una socialización al final que permitía validar la }\end{array}$ \\
\hline Teresa & llegar a acuerdos con & $\begin{array}{l}\text { Cada ejercicio tuvo una socialızacion al tinal que permitia validar la } \\
\text { coherencia de las propuestas y de lo allí construido. }\end{array}$ \\
\hline
\end{tabular}

${ }^{39}$ Aunque San Martín no cuenta con presencia de indígenas, afros y demás representaciones culturales, se recomienda en estos procesos tener un enfoque multicultural. 


\begin{tabular}{|c|c|c|}
\hline $\begin{array}{l}\text { Villarreal } \\
\text { Martínez) }\end{array}$ & $\begin{array}{l}\text { otros actores, deliberar y } \\
\text { concertar. }\end{array}$ & $\begin{array}{l}\text { Los espacios de trabajo pretendieron mezclar actores comunitarios, } \\
\text { productivos y de la institucionalidad pública. }\end{array}$ \\
\hline $\begin{array}{l}\text { (UN Public } \\
\text { Administrat }\end{array}$ & $\begin{array}{ll}\text { Los ciudadanos se } \\
\text { involucran en la } \\
\text { determinación de los } \\
\text { niveles de servicio }\end{array}$ & $\begin{array}{l}\text { Se priorizaron las problemáticas más comunes y las que sería más } \\
\text { pertinente atender en función de mejorar las condiciones para el } \\
\text { empleo y el emprendimiento. }\end{array}$ \\
\hline $\begin{array}{l}\text { ion } \\
\text { Programme) } \\
2012\end{array}$ & $\begin{array}{l}\text { Los ciudadanos se } \\
\text { involucran en las } \\
\text { prioridades } \\
\text { presupuestarias }\end{array}$ & $\begin{array}{l}\text { Se definieron los proyectos que contribuirían a la mitigación de la } \\
\text { mayoría de las causas de los problemas identificados, y desde el } \\
\text { equipo técnico de formulación se identificaron los posibles aliados } \\
\text { para financiar esas alternativas y los proyectos priorizados de } \\
\text { manera participativa, mencionadas en las tres líneas estratégicas. }\end{array}$ \\
\hline
\end{tabular}

Fuente: Elaboración propia 2017

Con los ejercicios generales definidos en las tablas anteriores y la descripción específica del apartado 1 y 2, se proponen los siguientes puntos de discusión, a manera de balance crítico, conclusiones y recomendaciones:

- El adecuado cumplimiento la normatividad y los espacios de participación existentes, permiten el ejercicio de formulación participativa de política pública, condiciones importantes para fortalecer los resultados y aumentar las posibilidades de éxito de esta y otro tipos de políticas.

- Para promover procesos de formulación participativa de políticas públicas es necesario convocar la participación de los actores pertinentes, como líderes comunitarios, empresarios y sector público, así como contar con apoyo 
económico y técnico que se articule con disposición política de la entidad territorial, sus representantes y la comunidad en general.

- El abandono estatal que manifestó la comunidad, y que podría interpretarse como debilidad institucional, es causa del desinterés de participar en escenarios de planeación participativa, asunto agravado por la falta de compromiso y de cumplimiento de las autoridades públicas y los actores privados en la implementación de los proyectos definidos de manera participativa.

- La importancia de la participación de la comunidad que resaltan los autores que han analizado el tema de formulación participativa de política pública, se evidenció en el ejercicio, pues gracias a sus aportes fue posible reconocer por consenso deliberativo y con claridad, cuáles eran las problemáticas que se debían atender, cómo y dónde se presentan y de qué manera es más viable y pertinente atenderlas.

- Una adecuada mediación técnica, desde una organización o entidad imparcial que tenga efectividad al convocar actores y al definir metodologías, puede contribuir al proceso y a la construcción de insumos que vinculan diferentes voces y perspectivas, todos ellos necesarios en este tipo de procesos.

- En este tipo de ejercicios donde el apoyo está enfocado a las entidades territoriales desde instituciones de carácter central, es muy importante contar con la intención de la alcaldía municipal y el concejo para aprobar e implementar la suma de acciones que resulten importantes en el ejercicio, 
tales como acuerdos municipales para lograr una incidencia real de este instrumento sobre otros instrumentos de planeación y sobre proyectos y acciones concretas.

- La parte estratégica y las acciones concretas que se han definido con la comunidad, tiene muchas similitudes con las acciones que se establecen en el plan de desarrollo actual del municipio y el departamento, lo que indica que es muy viable poder concretar las acciones propuestas si los futuros mandatarios atienden a la visión estratégica de la política pública de empleo y emprendimiento para San Martín Cesar.

- Dentro de las acciones que establezca la política púbica para su implementación es fundamental vincular espacios y grupos de seguimiento real en donde la comunidad cumpla un papel importante para garantizar la objetividad en el cumplimiento de las acciones y metas concertadas.

Algunas de las posibilidades abiertas para complementar esta o investigaciones de este tipo de investigaciones, pueden orientarse a identificar que sucede con la legitimización e incidencia del proceso es decir los mandatarios y sus asesores que tanto tienen en cuenta las propuestas definidas desde la comunidad para adoptar un documento oficial con trascendencia en el tiempo y que permee otro tipo de instrumentos. 


\section{5, Bibliografía}

Acosta, A. (2009). La maldición de la abundancia. Recuperado de: http://www.rebelion.org/docs/122604.pdf

Aguilar. L.F (2009). Marco para el análisis de las políticas públicas. En Mariñez F. y V. Garza Cantú (Coord.), Política pública y democracia en América Latina. Del análisis a la implementación. México: EGAP/CERALE/Miguel Ángel Porrúa, 1131.

Anónimo (26 de abril de 2012). Ecopetrol confirmo el hallazgo de un nuevo yacimiento de petrolero en el Cesar. El Pilón. Recuperado de http://elpilon.com.co/ecopetrolconfirmo-hallazgo-de-pozo-petrolero-en-el-cesar/Bobbio, N. (1989). Estado, gobierno y sociedad. Por una teoría general de la política. México: FCE.

Bobbio, (1989). Estado, gobierno y sociedad. Por una teoría general de la política. México: fondo de cultura económica.

Boudet, H., et al., "Fracking" controversy and communication: Using national survey data tounderstand public perceptions of hydraulic fracturing. Energy Policy (2013), citado por VALDÉS AGUIRRE, Claudia Lucía. "El fracking: impactos ambientales y socioeconómicos”. Madrid, España:p. 1-9

Casar, M., y Maldonado, C. (2010). Formación de agenda y procesos de toma de decisiones. Una aproximación desde la ciencia política. En Problemas, Decisiones y Soluciones: Enfoques de Política Pública, 207-238. México: FCE/CIDE.

Cefai D \& Terzi C. (2012) L'expérience des problèmes publics. Perspectives pragmatistes, Paris, EHESS, coll. Raisons pratiques

Chac, M. C. (2004). Las políticas públicas participativas, las organizaciones de base y la construcción de espacios públicos de concertación local. Consultado en: http://www. innovacionciudadana. cl/portal/imag en/File/canto. pdf.

Chevallier, Jacques. (1986). Ciencia administrativa: Teoría general de la institución administrativa, Instituto Nacional de Administración Pública, España. 
Cobb, R., y Elder,C. (1972). Participation in American Politics: The Dynamics of AgendaBuilding. Boston: Allyn and Bacon.

Cogan, C., y Sharpe, G. (1986). Planning Analysis: The Theory of Citizen Involvement. Recuperado de http://pages.uoregon.edu/rgp/PPPM 613/class10theory.htm

Cunill G, N. (1997). Repensando lo público a través de la sociedad. Nuevas formas de gestión pública y representación social. Venezuela: CLAD y Nueva Sociedad.

Decreto Nacional 1042, 1978. Colombia, Bogotá

Departamento Administrativo Nacional De Estadística. Conceptos básicos. Recuperado de: https://www.dane.gov.co/files/inf_geo/4Ge_ConceptosBasicos.pdf

Departamento Administrativo Nacional De Estadística. Proyecciones de población.

Recuperado de: https://www.dane.gov.co/index.php/estadisticas-portema/demografia-y-poblacion/proyecciones-de-poblacion

Departamento Nacional De Planeación .Fichas de Caracterización Territorial. Recuperado de: https://www.dnp.gov.co/programas/desarrollo-territorial/Paginas/Fichas-deCaracterizacion-Regional.aspx

Forero, C. (2000). El Sistema Nacional De Planeación Participativa De Colombia 19942000. En Sanchez Fernando.(presidencia). Seminario Funciones Básicas de la Planificación. Instituto Latinoamericano y del Caribe de Planificación Económica y Social - ILPES, CEPAL MEP del Gobierno de Cuba. La Habana, Cuba.

Galvis, M. (3 de julio de 2016). El acuerdo sobre participación política: ¿cómo será el proceso de apertura democrática?. Razón Publica. Recuperado de http://www.razonpublica.com/index.php/politica-y-gobierno-temas-27/9557-elacuerdo-sobre-participaci\%C3\%B3n-pol\%C3\%ADtica-\%C2\%BFc\%C3\%B3moser\%C3\%A1-el-proceso-de-apertura-democr\%C3\%A1tica.html

Garraud, P. (1990). “Politiques nationales, élaboration de l'Agenda”.Année sociologique, 40, Paris, 17-41. 
Gonzales, A. (10 de noviembre de 2013). La participación ciudadana en las decisiones minero-energéticas. Razón Publica. Recuperado de http://www.razonpublica.com/index.php/econom-y-sociedad-temas-29/7178-laparticipaci\%C3\%B3n-ciudadana-en-las-decisiones-mineroenerg\%C3\%A9ticas.html

Kawulich, Barbara B. (2006). La observación participante como método de recolección de datos [82 párrafos]. Forum Qualitative Sozialforschung / Forum: Qualitative Social Research [On-line Journal], 6(2), Art. 43, http://nbn-resolving.de/urn:nbn:de:0114fqs0502430.

Lasswell H \& Mc Dougal M (1992). (Jurisprudence for a free society: Studies in law,science,and policy, New haven press, new Haven

Lenoir, R. (1986). “Groupes de pression et groupes consensuels. Contribution à une analyse de la formation du droit”. Actes de la recherche en sciences sociales, 64, pp. 30-39

Martínez, P. C. (2006). El método de estudio de caso: Estrategia metodológica de la investigación científica. Pensamiento y gestión, 20(1), 165-193. Recuperado de http://ciruelo.uninorte.edu.co/pdf/pensamiento_gestion/20/5_El_metodo_de_estudio _de_caso.pdf

Meny, Y, \& Thoenig, J. (1992). La politicas públicas.Barcelona, España:Editorial Ariel. Barcelona.

Ministerio de Salud y Protección Social. Régimen contributivo. Recuperado de: https://www.minsalud.gov.co/proteccionsocial/Regimencontributivo/Paginas/regime n-contributivo.aspx

Ministerio de Salud y Protección Social. Régimen Subsidiado. Recuperado de: https://www.minsalud.gov.co/salud/Paginas/R\%C3\%A9gimenSubsidiado.aspx

Ministerio de Trabajo. Proyecto de decreto nacional sobre el trabajo decente. Recuperado de: http://www.mintrabajo.gov.co/documents/20147/6028064/PROYECTO+DECRET 
O+TRABAJO+DECENTE.pdf/f25d8529-e005-2a6b-acdb-

fc83b6d352ad?version=1.0

Ministerio de Trabajo. (21 de octubre de 2016) Decreto Único Reglamentario del Sector Trabajo. [Decreto 1668 de 2016]. Recuperado de: http://es.presidencia.gov.co/normativa/normativa/DECRETO\%201668\%20DEL\%2 021\%20DE\%20OCTUBRE\%20DE\%202016.pdf

Ministerio del Trabajo. normatividad legal vigente de la formación para el trabajo recuperado de: www.mintrabajo.gov.co/component/docman/doc.../1197-marcojuridico.html

Oficina del Alto Comisionado para la paz. (2016). Acuerdo final para la terminación del conflicto y la construcción de una paz estable y duradera. Recuperado de http://www.altocomisionadoparalapaz.gov.co

Palacio, T. (2011). Justicia y diferencia en Iris Marion Young: La repolitización de la sociedad a través de un nuevo concepto de justicia. Eikasia. Revista de Filosofía. Recuperado de: http://revistadefilosofia.com/39-04.pdf

Programa de las Naciones Unidas Para El Desarrollo. (2017). Bases para la formulación de la política pública de empleo y emprendimiento en San Martín Cesar, ETH, Bogotá

Roth, A. N. (2017). Políticas públicas: formulación, implementación y evaluación. Bogotá: Ediciones Aurora.

Stiglitz, J. (2006). Cómo hacer que funcione la globalización. Madrid, España: Taurus

Tamayo, A.,y Sánchez, L. (julio - diciembre de 2008). Sentidos contemporáneos de la planeación y el desarrollo. Planeación para el desarrollo integral del territorio. Bitacora ,(13), p.12.

Torres, A. \& Frey, K. (2015). Gobernanza y democracia desde la acción colectiva urbana. En: Acción colectiva, gestión territorial y gobernanza democrática en Bogotá. Bogotá: Ed. UPC, pp.225-263 
UN Public Administration Programme Publications 2012 Tomado de https://publicadministration.un.org/publications/content/un_pubs.html

Uprimny, R. (2001). “Constitución de 1991, Estado Social y derechos humanos: Promesas Incumplidas, Diagnósticos y perspectiva”. Diez años de la constitución colombiana. Memorias seminario de evaluación sobre la Constitución Política de Colombia, Bogotá, Colombia: Universidad Nacional de Colombia.

Uvalle, R. (2005). Ciudadanía y administración pública. En León y Ramírez, J. C. y J. C. Olvera García (Coords.), Los ciudadanos de cara al siglo XXI. México: El Colegio de México.

Velásquez. F. (23 de febrero de 2014) Dos décadas de participación ciudadana: la Ley 134 de 1994 al banquillo. Razon Publica. recuperado de: http://www.razonpublica.com/index.php/politica-y-gobierno-temas-27/7386-dosd\%C3\%A9cadas-de-participaci\%C3\%B3n-ciudadana-la-ley-134-de-1994-albanquillo.html

Villareal, M. (2009). Participación ciudadana y políticas públicas. Décimo Certamen de Ensayo Político. Nuevo León: Comisión Estatal Electoral.

Ziccardi, A. (1998). Gobernabilidad y participación ciudadana en la ciudad capital. México: UNAM y Miguel Ángel Porrúa.

Ziccardi, A. (1998). Gobernabilidad y participación ciudadana en la ciudad capital. Revista Mexicana de Sociología,60(3),267-270 .

Ziccardi, A. (2004).Espacios e instrumentos de participación ciudadana para las políticas sociales del ámbito loca 1. En Ziccardi, A. (Coord.), Participación ciudadana políticas sociales en el ámbito local (pp.245-272). México: UAM-Instituto de Investigaciones Sociales, Consejo Mexicano de Ciencias Sociales, Instituto Nacional de Desarrollo Social. 


\section{Anexos}

\section{Lista de tablas}

Tabla 1 Criterios de priorización de sectores potenciales económicamente ....................... 35

Tabla 2 Criterios de priorización de actividades/sectores productivos .............................. 38

Tabla 3 Evaluación de impacto y viabilidad de los sectores priorizados ........................... 39

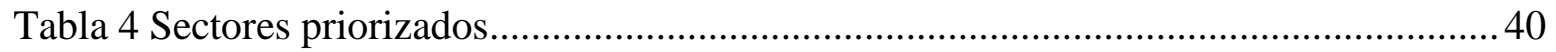

Tabla 5 Acciones y problemáticas a atender por la línea \#1 capacidades locales para promover, planear y gestionar oportunidades para el desarrollo productivo sostenible y el

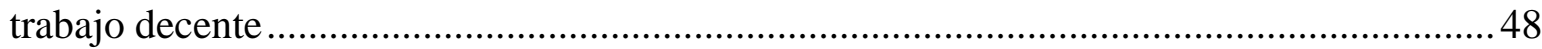

Tabla 6 Acciones y problemáticas a atender por la línea \#2 recursos, servicios, infraestructura, innovación y tecnología.

Tabla 7 Acciones y problemáticas a atender por la línea \#3 población con conocimientos, habilidades y destrezas

Tabla 8 Aproximaciones conceptuales sobre Problema público y agendamiento político: el Caso Política Pública de empleo y emprendimiento San Martín Cesar 53

Tabla 9 Aproximaciones conceptuales sobre Política Pública participativa: el Caso Política Pública de empleo y emprendimiento San Martín Cesar ..... .56

\section{Lista de figuras}

Figura 1 Momentos más relevantes para la planeación participativa en Colombia ............. 11 Figura 2 Hallazgos de prensa relacionado con el fracking en San Martín, 2016 -2017....... 21

Figura 3 Ubicación de San Martín en el departamento del Cesar y el País........................24

Figura 4 Pirámide poblacional de San Martín - Cesar 2012* - 2016* -2020* ................. 25

Figura 5 Valor agregado municipal 2013 ............................................................... 27

Figura 6 Síntesis momentos de formulación ............................................................ 32

Figura 7 problemáticas causas y efectos alrededor del desempleo ..................................4 43

Figura 8 problemáticas causas y efectos alrededor del emprendimiento ..........................44

Figura 9 problemáticas causas y efectos alrededor del trabajo decente ........................... 45 